\title{
Effects of diet type and supplementation of glucosamine, chondroitin, and MSM on body composition, functional status, and markers of health in women with knee osteoarthritis initiating a resistance-based exercise and weight loss program
}

\author{
Teresa Magrans-Courtney ${ }^{3+}$, Colin Wilborn ${ }^{2 \dagger}$, Christopher Rasmussen $^{1+}$, Maria Ferreira $^{4 \dagger}$, Lori Greenwood $^{1+}$, \\ Bill Campbell ${ }^{5 \dagger}$, Chad M Kerksick ${ }^{6 \dagger}$, Erica Nassar ${ }^{7 \dagger}$, Rui $\mathrm{Li}^{8+}$, Mike losia ${ }^{9 \dagger}$, Matt Cooke ${ }^{10 \dagger}$, Kristin Dugan ${ }^{2 \dagger}$, \\ Darryn Willoughby ${ }^{3 \dagger}$, LuAnn Soliah ${ }^{11 \dagger}$ and Richard B Kreider ${ }^{1 * \dagger}$
}

\begin{abstract}
Background: The purpose of this study was to determine whether sedentary obese women with knee OA initiating an exercise and weight loss program may experience more beneficial changes in body composition, functional capacity, and/or markers of health following a higher protein diet compared to a higher carbohydrate diet with or without GCM supplementation.

Methods: Thirty sedentary women (54 $\pm 9 \mathrm{yrs}, 163 \pm 6 \mathrm{~cm}, 88.6 \pm 13 \mathrm{~kg}, 46.1 \pm 3 \%$ fat, $33.3 \pm 5 \mathrm{~kg} / \mathrm{m}^{2}$ ) with clinically diagnosed knee OA participated in a 14-week exercise and weight loss program. Participants followed an isoenergenic low fat higher carbohydrate $(\mathrm{HC})$ or higher protein (HP) diet while participating in a supervised 30minute circuit resistance-training program three times per week for 14-weeks. In a randomized and double blind manner, participants ingested supplements containing 1,500 mg/d of glucosamine (as d-glucosamine HCL), 1,200 $\mathrm{mg} / \mathrm{d}$ of chondroitin sulfate (from chondroitin sulfate sodium), and $900 \mathrm{mg} / \mathrm{d}$ of methylsulfonylmethane or a placebo. At 0, 10, and 14-weeks, participants completed a battery of assessments. Data were analyzed by MANOVA with repeated measures.
\end{abstract}

Results: Participants in both groups experienced significant reductions in body mass (-2.4 $\pm 3 \%)$, fat mass (-6.0 $\pm 6 \%$, and body fat $(-3.5 \pm 4 \%)$ with no significant changes in fat free mass or resting energy expenditure. Perception of knee pain $(-49 \pm 39 \%)$ and knee stiffness $(-42 \pm 37 \%)$ was decreased while maximal strength $(12 \%)$, muscular endurance (20\%), balance indices (7\% to 20\%), lipid levels (-8\% to $-12 \%)$, homeostasis model assessment for estimating insulin resistance (-17\%), leptin (-30\%), and measures of physical functioning (59\%), vitality (120\%), and social function (66\%) were improved in both groups with no differences among groups. Functional aerobic capacity was increased to a greater degree for those in the HP and GCM groups while there were some trends suggesting that supplementation affected perceptions of knee pain $(p<0.08)$.

Conclusions: Circuit style resistance-training and weight loss improved functional capacity in women with knee OA. The type of diet and dietary supplementation of GCM provided marginal additive benefits.

Trial Registration: ClinicalTrials.gov: NCT01271218

\footnotetext{
* Correspondence: rkreider@hlkn.tamu.edu

+ Contributed equally

'Exercise \& Sport Nutrition Lab, Department of Health \& Kinesiology, Texas

A\&M University, College Station, TX 77843-4243, USA

Full list of author information is available at the end of the article
} 


\section{Background}

According to the Centers for Disease Control and Prevention (CDC), there are approximately 43 million Americans suffering from arthritis with 21 million affected by osteoarthritis $(\mathrm{OA})[1,2]$. It is believed that 1 in 10 or 4.3 million adults aged 60 and older in the United States of America have symptomatic knee OA [3] and 1 in 4 individuals may develop knee and/or hip OA during their lifetime [2]. The general incidence and prevalence of $\mathrm{OA}$ increases two to tenfold from age 30 to 65 years [4]. By 2020, the CDC estimates that 60 million Americans will have OA [1,2]. Former athletes and active individuals have been reported to be susceptible to knee OA as they age [5].

Symptoms of OA include disability of the joints caused by swelling, pain after exercise or use, and joint stiffness $[1,2]$. Although the cause of OA is unknown, it is believed that stress placed upon the joints is a factor. Treatments for OA vary and have included rest, heat, anti-inflammatory and pain-relieving medications, corticosteroid injections, and/or surgery [5]. Physical activity has been suggested to be beneficial for OA patients while inactivity can serve as a risk factor for developing OA [5]. Research from the Framingham Knee Osteoarthritis Study indicated that overweight men and women have a higher risk for developing OA than those who are not overweight [6]. These researchers also reported that weight loss helped decrease pain associated with OA [7]. Messier and colleagues [8] reported that weight loss significantly reduces load exertion on the knee. Moreover, Miller and associates [9] reported that an intensive energy deficit diet combined with exercise training improved physical function indices in older obese adults with knee OA. It has been reported that changes in OA symptoms were best predicted by changes body fat [10]. In addition, reductions in strength relative to body weight can promote the development of OA [11]. As a result, interventions that strengthen the muscles and reduce body fat have been suggested to reduce pain and enhance functional capacity in individuals with OA $[10,12,13]$.

Higher protein diets have been reported to promote greater weight loss while preserving fat free mass and resting energy expenditure to a greater degree than higher carbohydrate diets [14-16]. In addition, higher protein diets have been reported to promote greater improvement in several markers of health particularly in populations at risk to cardiovascular disease due to elevated glucose and/ or triglyceride levels [17-19]. Prior research from our lab has indicated that 14-weeks of circuit style resistancetraining while following a moderately hypo-energetic higher protein diet promoted significant reductions in weight and fat mass while improving fitness and markers of health in obese women $[20,21]$. A subsequent study indicated that this program was comparatively more effective in terms of promoting weight loss and improvements in markers of health and fitness than a meal replacement-based diet program with recommendations to increase physical activity [22]. Additionally, we have reported that higher protein diets promote more favorable changes in body composition and markers of health than a higher carbohydrate diet in obese women initiating training with and without insulin resistance [23]. Theoretically, adherence to a higher protein weight loss diet while participating in a resistance-training program may be more beneficial than a higher carbohydrate diet for patients with OA because it may promote greater reductions in fat mass, preserve fat free mass during weight loss, and promote greater improvements in functional status and markers of health.

Glucosamine sulfate supplementation in patients with knee pain has been reported to improve joint pain and function [24]. For example, Pavelka and colleagues [25] evaluated the effects of 3-years of glucosamine sulfate supplementation on progressive joint degeneration and symptoms associated with knee OA. Results indicated that markers of knee pain, physical function, and joints stiffness were improved. Similarly, Usha and coworkers [26] studied the efficacy and safety of combinations of glucosamine and methlysulfonylmethane (MSM) supplementation in patients with knee OA. The researchers found that supplementation with glucosamine and MSM reduced joint pain and swelling, while improving the physical function of the joints [26]. These findings and others indicate that glucosamine, chondroitin, and/or MSM supplementation may have some therapeutic benefits for OA patients. For this reason, dietary supplementation of glucosamine, chondroitin, and/or MSM has been recommended particularly for active individuals [5,27-29]. Theoretically, glucosamine, chondroitin, and MSM supplementation may provide additive benefits to individuals with knee OA initiating an exercise and weight loss program.

The purpose of this study was 1) to determine whether sedentary obese women with knee OA initiating an exercise and weight loss program will experience more favorable changes in body composition, functional status, and/ or markers of health when following a higher protein diet compared to a higher carbohydrate-based diet; 2) to determine whether dietary supplementation of glucosamine, chondroitin, and MSM during a weight loss and exercise program lessens symptoms of pain, improves functional capacity, and/or promotes greater health benefits in women with knee OA; and, 3) to determine whether there are any additive benefits of combining these strategies. It was hypothesized that all participants would experience beneficial changes in body mass, body composition, functional status, and markers of health. However, greater benefits would be observed in those 
following a higher protein diet with glucosamine, chondroitin, and MSM supplementation.

\section{Methods \\ Experimental design}

The study was conducted as a randomized, doubleblind, placebo-controlled parallel clinical trial conducted in a university research setting. Participants with physician diagnosed OA participated in the Curves ${ }^{\circledR}$ (Curves International, Waco, TX) fitness and weight management program for 14-weeks [30]. This program was selected because it offers higher carbohydrate and higher protein diets; incorporates circuit-style resistance training as the primary exercise modality; it has been found to be effective in promoting weight loss and improving markers of health and fitness in sedentary obese women [20-23]; it offers a joint support supplement containing GCM to its members; and, the program is widely available. Participants were randomly assigned to ingest in a double-blind and randomized manner either a placebo or a commercially available dietary supplement containing glucosamine, chondroitin, and MSM. Primary outcome measures included measures of pain and functional capacity. Secondary outcome measures included weight loss and body composition; serum blood and hormones; and, measures of quality of life. All participants were tested for changes in energy intake; anthropometrics; body composition; resting energy expenditure; cardiovascular and muscular fitness; balance and functional capacity; serum and whole blood clinical markers; hormonal profiles; pain indices; and, psychosocial parameters after 0,10 , and 14 weeks of training, dieting, and supplementation.

\section{Participants}

This research protocol was reviewed and approved by the university Institutional Review Board prior to initiation. Participants were recruited through area physicians, advertisements in local newspapers, campus flyers, and Internet advertisements. Interested participants were asked to contact the laboratory for an initial telephone pre-screening interview. General entrance criteria included being a female with physician diagnosed OA between the ages of 18-70 years with a body mass index (BMI) greater than $27 \mathrm{~kg} / \mathrm{m}^{2}$ and no recent participation in a diet or exercise program. Individuals who met initial entrance criteria were invited to attend a familiarization session in which the details of the study were explained, human subject consent forms were signed, and personal and medical history information obtained. Subjects were not allowed to participate in this study if they: 1.) were pregnant, became pregnant, or had a desire for pregnancy; 2.) had any metabolic disorder including known electrolyte abnormalities, heart disease, arrhythmias, diabetes, or thyroid disease; 3.) had a history of hypertension, hepatorenal, musculoskeletal, autoimmune, or neurological disease (other than knee OA); 4.) were taking thyroid, hyperlipidemic, hypoglycemic, or anti-hypertensive medications; 5.) had taken ergogenic levels of nutritional supplements that may affect muscle mass (e.g., creatine, HMB), anabolic/catabolic hormone levels (e.g., DHEA), or weight loss supplements (e.g., thermogenics) within three months prior to the start of the study; 6.) were ingesting any anti-inflammatory products two weeks before the start of the study or additional products during the study; 7.) reported any unusual adverse events associated with this study in which the supervising physician recommended removal from the study; 8.) had significant injury or surgery to the lower extremity or spine within the last six months; 9.) did not indicate a minimal amount of perceived pain and physical function limitation on inventories used in the study; 10.) had severe arthritis that required surgery and greatly limited functionality (inability to perform lunge); or, 11.) had arthritis that required the current use of physiotherapy modalities.

Figure 1 presents a flow diagram of study enrollment, allocation, follow-up, and analysis. A total of 42 women met initial phone screening criteria and were invited to familiarization sessions. Of these, 32 women met entrance criteria and were medially-cleared to participate in the study by a research nurse and their personal physician. A total of 30 women completed the study. Those who dropped out of the study did so due to time constraints unrelated to the exercise, diet, and/or supplementation program. Participants were $54 \pm 9$ years old, $163 \pm 6 \mathrm{~cm}$ tall, weight $88.6 \pm 13 \mathrm{~kg}$, had a body fat percentage of $46.1 \pm 3 \%$, and had a BMI of $33.3 \pm 5 \mathrm{~kg} / \mathrm{m}^{2}$.

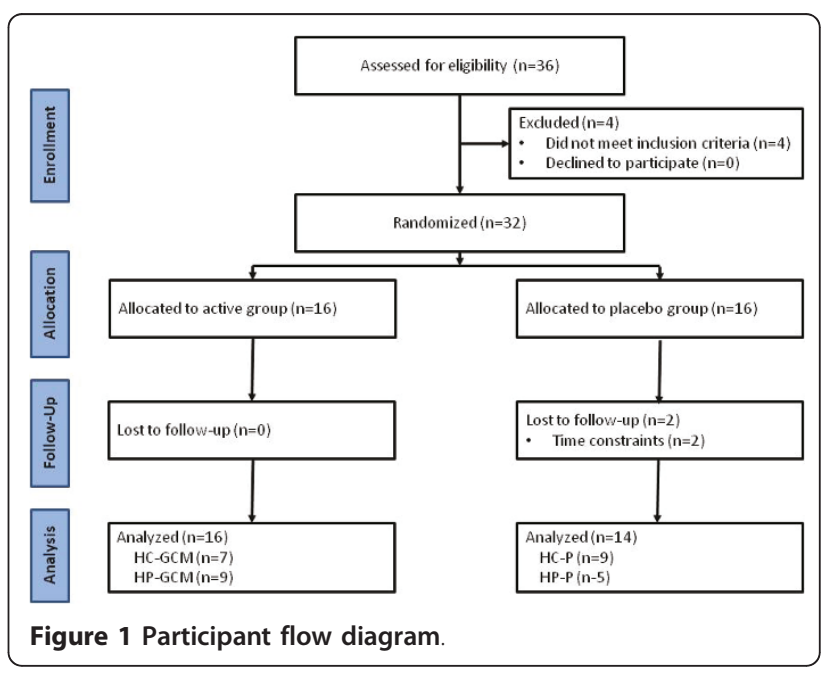




\section{Testing sequence}

Participants underwent a detailed orientation and familiarization/practice session prior to baseline testing. This included an explanation of the methods of the study and how to adhere to the diet; an opportunity to practice testing procedures; and, familiarization to the exercise training equipment. Participants recorded all food and fluid intake on dietary record forms 4-days before each testing session for weeks $0,10,14$. The dietary record included three days during the week and one weekend day. Participants were also asked to refrain from vigorous physical activity, alcohol intake, and ingestion of over the counter medications for 24-hours prior to testing. In addition, participants fasted for 12-hours prior to reporting to the laboratory. All testing was conducted in the early morning hours in order to control for diurnal variations in hormone levels.

Once reporting to the lab, participants completed a series of questionnaires that included the SF-36 quality of life (QOL) inventory; a Visual Analog Scale (VAS) to assess knee pain; and, the Western Ontario and McMasters University Osteoarthritis Index to assess knee function. Participants were then weighed, had total body water determined by multi-frequency bioelectrical impedance (BIA), and had body composition determined using dual-energy $x$-ray absorptiometry (DEXA). Following these assessments, participants had their blood pressure and resting heart rate determined using standard procedures. Participants then donated approximately $20 \mathrm{ml}$ of fasting blood using venipuncture techniques of an antecubital vein in the forearm according to standard procedures. Following blood collection, participants had measurements taken of their knees to include knee circumference to determine swelling secondary to osteoarthritis and active range of motion to assess knee flexibility. The participants then performed sit to stand, step-up and over, and forward lunge balance and functional capacity assessments. Participants then performed a knee extension and flexion muscular strength and endurance test using an isokinetic dynamometer. Next, participants performed a maximal cardiopulmonary exercise stress test to assess symptom limited functional peak aerobic capacity. Finally, participants performed an upper body muscular strength and endurance bench press test. Participants completed weekly a medical safety/side effect report that was analyzed by the lab research nurse.

\section{Dietary intervention}

All subjects followed the Curves ${ }^{\circledR}$ exercise and weight loss program (Curves International, Waco, TX) that is designed to improve fitness and promote weight loss in women [30]. Participants were assigned to follow isoenergetic low fat diets with higher protein (HP) or higher carbohydrate $(\mathrm{HC})$ macronutrient content based on their responses to a carbohydrate tolerance questionnaire as per diet guidelines. In both diets, participants were instructed to consume 1,200 kcals/d for 1-week (Phase I) and 1,600 kcals/d for 9-weeks (Phase II) during a 10 -week active weight loss period. Participants following the $\mathrm{HC}$ diet were instructed to consume a diet containing $55 \%$ carbohydrate, $15 \%$ protein, and $30 \%$ fat. Subjects in the HP group were asked to follow a diet containing $7 \%$ carbohydrate, $63 \%$ protein, and 30\% fat during Phase I of the diet and $15 \%$ carbohydrate, $55 \%$ protein, and $30 \%$ fat during Phase II of the diet. The final 4-weeks of the diet (Phase III) served as a weight maintenance period. Participants were instructed to consume 2,600 kcals d $\mathrm{d}^{-1}$ consisting of $55 \%$ carbohydrate, $15 \%$ protein, and $30 \%$ fat and to follow their respective Phase I diet $(1,200 \mathrm{kcals} / \mathrm{d})$ for 2-days only if they gained $1.35 \mathrm{~kg}$ (3 lbs) during the maintenance period. Participants were given diet plans and menus to follow at the start of the study and met with a registered dietitian and/or exercise physiologist at each testing session and every two weeks during the course of the study to discuss diet and exercise compliance. Previous research has demonstrated that this 14-week program promoted a 3-5 kg weight loss while maintaining resting energy expenditure in sedentary obese women [20-23].

\section{Supplementation protocol}

Participants were randomly assigned to ingest in a doubleblind manner caplets containing a commercially available supplement containing GCM (Curves Joint and Connective Support ${ }^{\mathrm{TM}}$, Curves International, Waco, TX) or a similarly prepared dextrose containing placebo $(\mathrm{P})$ for double blind administration. The GCM supplement provided a total of $1,500 \mathrm{mg} / \mathrm{d}$ of glucosamine (from d-glucosamine $H C L$ ), $1,200 \mathrm{mg} / \mathrm{d}$ of chondroitin sulfate (from chondroitin sulfate sodium), $120 \mathrm{mg} / \mathrm{d}$ of niacin, $120 \mathrm{mg} / \mathrm{d}$ of sodium, $45 \mathrm{mg} /$ $\mathrm{d}$ of zinc, $900 \mathrm{mg} / \mathrm{d}$ of MSM, $300 \mathrm{mg} / \mathrm{d}$ of boswellia serrata extract, $180 \mathrm{mg} / \mathrm{d}$ of white willow bark extract, and $15 \mathrm{mg} / \mathrm{d}$ of rutin powder. Participants ingested three caplets in the morning and the remaining three caplets in the evening 30-min before a meal for 14-weeks. The supplements were prepared in caplet form and packaged in generic bottles for double blind administration by Nutra Manufacturing (Greenville, SC). The dextrose placebo was prepared with a similar base material and color coated in order to have a similar appearance and aroma as the GCM supplement. Supplementation compliance was monitored by having the participants return empty bottles of the supplement at the end of each testing phase. In addition, internal monitoring of supplementation compliance occurred with participants signing a compliance statement in a post-study questionnaire. 


\section{Training protocol}

All subjects participated in the Curves supervised exercise program three days per week throughout the fourteen week protocol (a total of 42 workouts). Each circuit-style workout consisted of 14 exercises (e.g. elbow flexion/ extension, knee flexion/extension, shoulder press/lat pull, hip abductor/adductor, chest press/seated row, horizontal leg press, squat, abdominal crunch/back extension, pec deck, oblique, shoulder shrug/dip, hip extension, side bends and stepping). The exercise machines contained calibrated pneumatic resistance pistons that allowed for opposing muscle groups to be trained in a concentric-only fashion. Participants were informed of proper use of all equipment and were instructed to complete as many repetitions in a 30-s time period. In a continuous, interval fashion, participants performed floor-based callisthenic (e.g. running/skipping in place, arm circles, etc.) exercises on recovery pads for a 30-s time period after each resistance exercise in an effort to maintain a consistent exercise heart rate that corresponded to $60 \%$ to $80 \%$ of their heart maximum heart rate. All workouts were supervised by trained fitness instructors who assisted with proper exercise technique and maintenance of adequate exercise intensity. Participants were required to complete two rotations through all exercises which corresponded to exercising for approximately 28-min followed by a standardized whole-body stretching routine. Compliance to the exercise program was set a priori at a minimum of $70 \%$ compliance (30/42 exercise sessions).

\section{Procedures}

Diet assessment

Participants recorded all food and fluid intake for four days prior to each testing session. This included three weekdays and one weekend day. Dietary inventories were reviewed by a registered dietitian and subsequently analyzed for average energy and macronutrient intake using the ESHA Food Processor (Version 8.6) Nutritional Analysis software (ESHA Research Inc., Salem, OR).

\section{Body composition}

Height and body mass were determined according to standard procedures using a calibrated electronic scale (Cardinal Detecto Scale Model 8430, Webb City, Missouri) with a precision of $+/-0.02 \mathrm{~kg}$. Intracellular, extracellular, and total body water was assessed using a Xitron 4200 Bioelectrical Impedance Analyzer (Xitron Technologies, Inc., San Diego, $C A$ ) in order to monitor hydration status among testing sessions. Bone density and body composition (excluding cranium) were assessed using a Hologic Discovery W (Hologic Inc., Waltham, MA) dual energy x-ray absorptiometer (DXA) equipped with APEX Software (APEX Corporation Software, Pittsburg, PA). Mean coefficients of variation for bone mineral content and bone mineral density measurements performed on the spine phantom ranged between $0.41-0.55 \%$. Test-retest reliability studies performed with this DXA machine have previously yielded mean coefficients of variation for total bone mineral content and total fat free/soft tissue mass of 0.31 $0.45 \%$ with a mean intra-class correlation of 0.985 [31].

\section{Resting energy expenditure}

Resting energy expenditure (REE) was assessed using a ParvoMedics TrueMax 2400 Metabolic Measurement System (ParvoMedics, Inc., Sandy, UT). This test was a nonexertional test performed in a fasted state with the participants lying supine on an exam table. A clear, hard plastic hood and soft, clear plastic drape was placed over the participants' neck and head in order to determine resting oxygen uptake and energy expenditure. All participants remained motionless without falling asleep for approximately 20 minutes. Data were recorded after the first ten minutes of testing during a five minute period of time in which criterion variables (e.g., $\mathrm{VO}_{2} \mathrm{~L} / \mathrm{min}$ ) changed less than $5 \%$. Test-retest measurements on 14 participants from a study previously reported [20] revealed that testretest correlations $(\mathrm{r})$ of collected $\mathrm{VO}_{2}$ in $1 /$ min ranged from $0.315-0.901(\bar{X}: 0.638)$ and coefficient of variation ranged from $8.2 \%-12.0 \%(\bar{X}: 9.9 \%)$ with a mean intraclass coefficient of $0.942, \mathrm{p}<0.001$.

\section{Anthropometrics}

Active range of motion for right/left knee extension and flexion was measured with a standard 12 " goniometer to determine knee range of motion. The participant was made to lie supine with one leg extended and the other leg bent with the heel resting on table. The extended leg was measured for knee extension. Next, the measurement of the same leg was measured for flexion range of motion by having the participant raise the extended leg slightly off the table and bring the heel toward the gluteus maximus. These procedures were repeated on the opposite leg. Test to test reliability of performing these tests were $0.75-0.98$. Knee circumference was measured as a general indicator of knee inflammation/swelling. The participant lied supine with one leg extended and the other leg bent with the heel resting on table. The circumference of the extended leg was measured and then repeated on the opposite leg. Measurements were performed utilizing a Gulick anthropometric tape (Model J00305, Lafayette Instruments, Lafayette, IN) at the joint line of both knees. Test to test reliability of performing these tests were $0.86-0.92$.

\section{Exercise capacity}

Resting heart rate was determined by palpitation of the radial artery using standard procedures [32]. Blood 
pressure was assessed by auscultation of the brachial artery using a mercurial sphygmomanometer using standard clinical procedures [32]. Resting heart rate and blood pressure measurements were taken on the participant in the supine position after resting for 5-min. Participants were attached to the Quinton 710 ECG (Quinton Instruments, Bothell, WA) and walked on a Trackmaster TMX425C treadmill (JAS Fitness Systems, Newton, KS). Resting expired gases were collected using the Parvo Medics 2400 TrueMax Metabolic Measurement System. The participant then performed a standard symptomlimited maximal Bruce treadmill exercise test according to standard procedures [32]. Calibration of gas and flow sensors was completed every morning prior to testing and was found to be within $3 \%$ of the previous calibration point.

A standard isotonic Olympic bench press (Nebula Fitness, Versailles, $\mathrm{OH}$ ) was used for the isotonic bench press tests. A one repetition maximum (1 RM) test was performed using standard procedures. Following determination of the participants $1 R M$, subjects performed a bench press muscular endurance test at $70 \%$ of $1 \mathrm{RM}$. Test to test reliability of performing these strength tests in our lab on resistance-trained participants have yielded low mean coefficients of variation and high reliability for the bench press $(1.9 \%$, intra-class $r=0.94)$.

Isokinetic testing was performed using the Biodex Multijoint Isokinetic Testing System (Biodex Medical Systems, Shirley, NY) to measure knee strength and endurance. Isokinetic strength was assessed bilaterally. Testing began from a dead stop with the participants' leg at 90 degrees of flexion and consisted of five, ten, and fifteen maximal voluntary concentric reciprocal knee extension and flexion repetitions at three different test speeds. Velocities were presented in a fixed order at 60, 180 and 300 degrees per second with one-minute rest between bouts. Fatigue index was calculated as the change in average force produced from the first to last third of each set of work performed. Positive values represent the percentage decline in force generation over the set while negative values represent an increase in average force generated at the latter third of the set of repetitions. Test-to-test reliability data for women with osteoarthritis has been reported to vary from 0.83 to 0.94 [33].

\section{Balance and functional assessment}

Measurements of balance and functional capacity were obtained using the Neurocom SmartEquitest ${ }^{\circledR}$ (Neurocom International, Portland, OR). Data were collected on postural balance and mobility utilizing the sit to stand, step up and over, and forward lunge tests following standardized procedures. Test-to-test reliability in women aged 65-75 has been reported to be $r=0.92$ [34].

\section{Blood collection and analysis}

Fasted whole blood and serum samples were collected using standard phlebotomy techniques. Whole blood samples were analyzed for complete blood counts with platelet differentials using an Abbott Cell Dyn 3500 (Abbott Laboratories, Abbott Park, IL) automated hematology analyzer. Serum samples were analyzed for a complete metabolic panel using a calibrated Dade Behring Dimension RXL (Siemans AG, Munich, Germany) automated clinical chemistry analyzer. Coefficient of variation $(\mathrm{CV})$ for the tests using this analyzer was similar to previously published data for these tests (range: 1.0 to $9.6 \%)$ [35].

Serum C-Reactive Protein, IL-6, TNF- $\alpha$, cortisol, and leptin were determined with either enzyme linked immuno-absorbent assay (ELISA) or enzyme immunoabsorbent assay (EIA) kits (Cayman Chemical, AnnArbor, MI; Diagnostic Systems Laboratories, Webster, TX) using a Wallac Victor-1420 microplate reader (Perkin-Elmer Life Sciences, Boston, MA) at a dual wavelength absorbance of 405 or $450 \mathrm{~nm}$ according to kit specifications. Intra-assay and inter-assay coefficient of variation were, respectively, 5.3-6.7\% and $8.2-9.7 \%$ for TNF- $\alpha$; $4.7-8.3 \%$ and $6.70-10.0 \%$ for IL-6; $6.9 \%$ and $13.1 \%$ for C-Reactive protein; and, 2.4-10.3\%, and $8.0-12.0 \%$ for cortisol. The homeostasis model assessment for estimating insulin resistance $\left(\mathrm{HOMA}_{\mathrm{IR}}\right)$ was calculated as the product of fasting glucose times fasting insulin expressed in conventional units divided by 405 [36].

\section{Psychosocial and pain questionnaires}

Participants completed the SF-36 Quality of Life (QOL) inventory to determine changes in quality of life scores throughout the length of the study [37]. The SF-36 QOL inventory assesses a number of physical and mental components including physical functioning (i.e., ability to perform most vigorous physical activities without limitation to health); role physical (i.e., ability to work and perform daily activities); bodily pain (i.e., limitations due to pain); general health (i.e., assessment of personal health); vitality (i.e., feelings of energy); social functioning (i.e., ability to perform normal social activities); role emotion (i.e., problems with work or other daily activities); and, mental health (state of feelings of peacefulness, happiness, and calm). This instrument has been shown to be a valid indicator of psychosocial dimensions that may be influenced by general improvements in health and/or weight loss. Perceived knee pain was determined using a Visual Analogue Scale (VAS) following procedures developed by Denegar \& Perrin [38]. In addition, the Western Ontario and McMasters University Osteoarthritis Index (WOMAC ${ }^{\mathrm{TM}} 3.1$ Index) was used to assess dimensions of pain, joint stiffness and disability in knee and hip osteoarthritis using a battery of 24 questions [39]. 


\section{Statistical analysis}

Baseline demographic data (i.e., age, height, weight, percent body fat, BMI) were analyzed by one-way analysis of variance (ANOVA). Data were normally distributed and did not require transformation prior to statistical analysis. Related variables were grouped together and analyzed by multivariate analysis of variance (MANOVA) with repeated measures (PASW Statistics 18.0.2 [Release April 2, 2010], SPSS Headquarters, Chicago, IL). Non-correlated variables were analyzed by repeated measures ANOVA. Delta values were calculated and analyzed on select variables by ANOVA for repeated measures to assess changes from baseline values. Data were considered statistically significant when the probability of type I error was 0.05 or less. In some instances, quadratic interaction p-levels are reported indicating that non-linear but significant differences were observed between groups over time. Tukey's Least Significant Difference (LSD) post-hoc analyses were performed when a significant interaction was observed to determine where significance was obtained. Effect sizes were calculated using Cohen's d statistic to quantify the size and significance that may exist between groups independent of group size. Power calculations on changes observed in WOMAC scores indicated that an n-size of 8-10 per group would yield sufficient power ( $>0.8$ ) values. Additionally, power calculations on weight loss changes previously observed in similar studies indicated that a sample size of $10-15$ per group yielded moderate to high power (>0.8) values [20-22].

\section{Results}

A total of 30 participants completed the study $(54 \pm 9 \mathrm{yrs}$, $163 \pm 6 \mathrm{~cm}, 88.6 \pm 13 \mathrm{~kg}, 46.1 \pm 3 \%$ fat, $33.3 \pm 5 \mathrm{~kg} / \mathrm{m}^{2}$ ). Of these, 16 participants in the GCM group completed the study ( $52 \pm 10 \mathrm{yrs}, 164 \pm 7 \mathrm{~cm}, 89.7 \pm 13 \mathrm{~kg}, 45.9 \pm$ $3 \%$ fat, $33.3 \pm 4 \mathrm{~kg} / \mathrm{m}^{2}$ ) while 14 participants in the $\mathrm{P}$ group completed the study $(57 \pm 7$ yrs, $162 \pm 6 \mathrm{~cm}, 87.3 \pm$ $14 \mathrm{~kg}, 46.4 \pm 4 \%$ fat, $\left.33.2 \pm 5 \mathrm{~kg} / \mathrm{m}^{2}\right)$. No significant differences were observed between groups on baseline demographic data.

\section{Energy intake}

Table 1 presents dietary intake data observed for the diet and supplement groups. The diet intervention significantly reduced energy intake in both groups over time. As expected, carbohydrate intake was greater in the $\mathrm{HC}$ group while protein intake was greater in the HP group during the 10-week diet phase. Dietary supplementation had no influence on macronutrient intake.

\section{Body composition and resting energy expenditure}

Table 2 presents body composition and REE results observed among groups during the course of the study while Figure 2 presents changes from baseline in body composition values. Dieting and training significantly decreased body mass $(-2.1 \pm 3 \mathrm{~kg}$ or $-2.4 \pm 3 \%)$, fat mass $(-2.3 \pm 2.4 \mathrm{~kg}$ or $-6.0 \pm 6 \%)$, and percent body fat $(-1.6 \pm 1.9 \%$ or $-3.5 \pm 4 \%)$ in both groups over time while fat free mass and REE were maintained. Type of diet and supplementation had no significant effects on changes in body composition or REE.

\section{Knee anthropometric measurements}

Table 3 presents knee range of motion and circumference data. No significant time $\times$ diet, time $\times$ supplement, or time $\times$ diet $\times$ supplement interactions were observed among groups in knee range of motion or circumference measures. However, left leg knee extension and flexion range of motion was significantly improved over time in both groups as a result of training.

\section{Exercise capacity}

Table 4 shows peak aerobic capacity, upper body muscular strength, and upper body muscular endurance data observed throughout the study. Exercise training significantly increased symptom-limited peak $\mathrm{VO}_{2}(5 \%)$, bench press $1 \mathrm{RM}$ strength (12\%), and upper body bench press muscular endurance at $70 \%$ of 1 RM (20\%). Peak aerobic capacity was increased to a greater degree in the HP and GCM groups. No significant time $\times$ diet, time $\times$ supplement, or time $\times$ diet $\times$ supplement interactions were observed among groups in bench press 1RM strength or endurance. However, participants in the HP group produced more total lifting volume during the muscular endurance test than those in the HC group. Exercise training, diet, and supplementation had no effects on resting heart rate, systolic blood pressure or diastolic blood pressure.

Results from isokinetic knee extension and flexion tests are presented in Table 5. No significant group or group $\times$ time interactions were observed. Therefore, data are presented for mean time effects. Training significantly increased knee extension and flexion peak torque values in each set of maximal voluntary contractions studied. Average gains in knee extension peak torque strength was $8-13 \%$ when performing 5 repetitions at $60 \mathrm{deg} / \mathrm{sec}$, $12-22 \%$ when performing 10 repetitions at $180 \mathrm{deg} / \mathrm{sec}$, and $12-19 \%$ when performing 15 repetitions at $300 \mathrm{deg} /$ sec. Similarly, knee flexion peak torque increased by $26-28 \%, 45-46 \%$, and $30-38 \%$ during the three exercise bouts, respectively. There was also evidence that training influenced fatigue index responses.

\section{Balance and functional capacity}

Table 6 presents functional balance testing results. No significant group or group $\times$ time interactions were observed. Therefore, data are presented for mean time 
Table 1 Dietary intake data for the diet and supplement groups

\begin{tabular}{|c|c|c|c|c|c|}
\hline Variable & Group & 0 & $\begin{array}{c}\text { Week } \\
10\end{array}$ & 14 & $p$-value \\
\hline \multirow{9}{*}{$\begin{array}{l}\text { Energy Intake } \\
\text { (kcals/d) }\end{array}$} & HC-GCM & $2,356 \pm 690$ & $1,906 \pm 571$ & $2,001 \pm 241$ & $D=0.08$ \\
\hline & $\mathrm{HC}-\mathrm{P}$ & $1,760 \pm 695$ & $1,689 \pm 439$ & $1,837 \pm 617$ & $S=0.64$ \\
\hline & HP-GCM & $1,775 \pm 424$ & $1,398 \pm 411$ & $1,441 \pm 295$ & $T=0.06_{q}$ \\
\hline & HP-P & $1,696 \pm 361$ & $1,562 \pm 165$ & $1,903 \pm 274$ & $T \times D=0.80$ \\
\hline & $\mathrm{HC}$ & $1,987 \pm 730$ & $1,768 \pm 475$ & $1,896 \pm 503$ & $\mathrm{~T} \times \mathrm{S}=0.18$ \\
\hline & $\mathrm{HP}$ & $1,746 \pm 377$ & $1,459 \pm 333$ & $1,614 \pm 358$ & $\mathrm{~T} \times \mathrm{D} \times \mathrm{S}=0.94$ \\
\hline & GCM & $2,046 \pm 610$ & $1,623 \pm 527$ & $1,690 \pm 390$ & \\
\hline & $\underline{P}$ & $1,741 \pm 593$ & $1,651 \pm 372$ & $1,857 \pm 521$ & \\
\hline & Mean & $1,886 \pm 605$ & $1,638 \pm 439 \dagger$ & $1,778 \pm 459$ & \\
\hline \multirow{9}{*}{$\begin{array}{l}\text { Carbohydrate } \\
\text { (g/d) }\end{array}$} & $\overline{\mathrm{HC}-\mathrm{GCM}}$ & $342 \pm 103$ & $228 \pm 87$ & $248 \pm 57$ & $D=0.02$ \\
\hline & HC-P & $189 \pm 82$ & $218 \pm 70$ & $238 \pm 117$ & $S=0.94$ \\
\hline & HP-GCM & $191 \pm 65$ & $125 \pm 61$ & $151 \pm 38$ & $T=0.015 \mathrm{q}$ \\
\hline & HP-P & $216 \pm 39$ & $143 \pm 106$ & $269 \pm 58$ & $\mathrm{~T} \times \mathrm{D}=0.63$ \\
\hline & $\mathrm{HC}$ & $245 \pm 115$ & $221 \pm 72$ & $241 \pm 96$ & $\mathrm{~T} \times \mathrm{S}=0.07$ \\
\hline & $\underline{\mathrm{HP}}$ & $200 \pm 55$ & $132 \pm 76$ & $196 \pm 84$ & $\mathrm{~T} \times \mathrm{D} \times \mathrm{S}=0.12_{\mathrm{q}}$ \\
\hline & GCM & $256 \pm 11$ & $171 \pm 87 \dagger$ & $194 \pm 67$ & \\
\hline & P & $197 \pm 71$ & $196 \pm 84$ & $247 \pm 100 \dagger$ & \\
\hline & Mean & $226 \pm 94$ & $184 \pm 85 \dagger$ & $222 \pm 88$ & \\
\hline \multirow{9}{*}{$\begin{array}{l}\text { Protein } \\
\text { (g/d) }\end{array}$} & $\overline{H C-G C M}$ & $88 \pm 24$ & $81 \pm 22$ & $75 \pm 20$ & $D=0.22$ \\
\hline & HC-P & $76 \pm 24$ & $77 \pm 16$ & $79 \pm 22$ & $S=0.97$ \\
\hline & HP-GCM & $79 \pm 4$ & $101 \pm 31$ & $83 \pm 14$ & $T=0.019_{q}$ \\
\hline & HP-P & $63 \pm 11$ & $133 \pm 70$ & $76 \pm 11$ & $T \times D=0.017_{q}$ \\
\hline & $\mathrm{HC}$ & $80 \pm 23$ & $77 \pm 16$ & $78 \pm 20$ & $\mathrm{~T} \times \mathrm{S}=0.35$ \\
\hline & $\mathrm{HP}$ & $73 \pm 10$ & $113 \pm 47 \dagger$ & $80 \pm 13$ & $T \times D \times S=0.19 q$ \\
\hline & $\overline{\mathrm{GCM}}$ & $83 \pm 16$ & $92 \pm 28$ & $80 \pm 16$ & \\
\hline & $\mathrm{P}$ & $72 \pm 21$ & $94 \pm 44$ & $78 \pm 19$ & \\
\hline & Mean & $77 \pm 19$ & $93 \pm 37 \dagger$ & $79 \pm 17$ & \\
\hline \multirow{9}{*}{$\begin{array}{l}\text { Fat } \\
(\mathrm{g} / \mathrm{d})\end{array}$} & HC-GCM & $78 \pm 24$ & $78 \pm 24$ & $82 \pm 10$ & $D=0.25$ \\
\hline & HC-P & $70 \pm 39$ & $59 \pm 18$ & $62 \pm 19$ & $S=0.26$ \\
\hline & HP-GCM & $79 \pm 21$ & $52 \pm 21$ & $59 \pm 22$ & $T=0.085_{q}$ \\
\hline & HP-P & $65 \pm 32$ & $53 \pm 6$ & $63 \pm 8$ & $T \times D=0.50$ \\
\hline & $\overline{\mathrm{HC}}$ & $73 \pm 33$ & $65 \pm 20$ & $69 \pm 19$ & $\mathrm{~T} \times \mathrm{S}=0.85$ \\
\hline & $\mathrm{HP}$ & $74 \pm 24$ & $53 \pm 16$ & $60 \pm 18$ & $\mathrm{~T} \times \mathrm{D} \times \mathrm{S}=0.33$ \\
\hline & GCM & $79 \pm 21$ & $63 \pm 23$ & $69 \pm 21$ & \\
\hline & $\mathrm{P}$ & $63 \pm 35$ & $60 \pm 15$ & $62 \pm 16$ & \\
\hline & Mean & $73 \pm 29$ & $60 \pm 19+$ & $65 \pm 18$ & \\
\hline
\end{tabular}

Data are means \pm standard deviations. $\mathrm{HC}=$ high carbohydrate diet, $\mathrm{HP}=$ high protein diet, $\mathrm{GCM}=$ glucosamine/chondroitin $/ \mathrm{MSM}$ group, $\mathrm{P}=$ placebo group, $\mathrm{FFM}=\mathrm{fat}$ free mass, $\mathrm{REE}=$ resting energy expenditure, $\mathrm{D}=$ diet, $\mathrm{S}=$ supplement, $\mathrm{T}=$ time. $\mathrm{q}=$ quadratic alpha level. $\dagger$ Indicates $\mathrm{p}<0.05$ difference from baseline.

effects. Training had no effects on weight transfer, rising index, or sway velocity measures obtained during the sit to stand test. However, lift-up index increased by $8-12 \%$ and movement time decreased by $15 \%$ in the step up and over knee function test. In the forward lunge knee function test, lunge distance was significantly increased (7-9\%) while contact time $(-19$ to $-20 \%)$ and force impulse $(-17$ to $-19 \%)$ values decreased.

\section{Blood samples}

Table 7 shows serum blood and hormone markers observed among groups during the study. No significant group or group $x$ time interactions were observed among groups. Therefore, data are presented for mean time effects. Training and dieting significantly decreased total cholesterol $(-8 \%)$, low-density lipoproteins $(-12 \%)$, high density lipoproteins $(-12 \%)$, blood urea nitrogen 
Table 2 Body composition and resting energy expenditure data

\begin{tabular}{|c|c|c|c|c|c|}
\hline Variable & Group & 0 & $\begin{array}{c}\text { Week } \\
10\end{array}$ & 14 & $p$-value \\
\hline \multirow{9}{*}{$\begin{array}{l}\text { Weight } \\
(\mathrm{kg})\end{array}$} & HC-GCM & $88.0 \pm 14$ & $87.0 \pm 16$ & $87.4 \pm 13$ & $D=0.75$ \\
\hline & $\mathrm{HC}-\mathrm{P}$ & $86.8 \pm 13$ & $84.8 \pm 14$ & $84.1 \pm 13$ & $S=0.70$ \\
\hline & HP-GCM & $91.0 \pm 13$ & $89.2 \pm 14$ & $87.9 \pm 13$ & $\mathrm{~T}=0.001$ \\
\hline & HP-P & $88.2 \pm 17$ & $86.4 \pm 15$ & $86.8 \pm 15$ & $T \times D=0.60$ \\
\hline & $\mathrm{HC}$ & $87.4 \pm 13$ & $85.8 \pm 14$ & $85.5 \pm 14$ & $\mathrm{~T} \times \mathrm{S}=0.84$ \\
\hline & $\mathrm{HP}$ & $90.0 \pm 14$ & $87.6 \pm 14$ & $87.5 \pm 13$ & $\mathrm{~T} \times \mathrm{D} \times \mathrm{S}=0.10$ \\
\hline & $\overline{G C M}$ & $89.7 \pm 13$ & $87.6 \pm 14$ & $87.7 \pm 14$ & \\
\hline & $\underline{P}$ & $87.3 \pm 14$ & $85.3 \pm 14$ & $85.1 \pm 13$ & \\
\hline & Mean & $88.6 \pm 13$ & $86.6 \pm 14 \dagger$ & $86.5 \pm 13 \dagger$ & \\
\hline \multirow{9}{*}{$\begin{array}{l}\text { Fat Mass } \\
(\mathrm{kg})\end{array}$} & HC-GCM & $37.5 \pm 7$ & $36.3 \pm 9$ & $35.8 \pm 8$ & $D=0.81$ \\
\hline & HC-P & $37.8 \pm 8$ & $36.1 \pm 9$ & $35.4 \pm 8$ & $S=0.98$ \\
\hline & HP-GCM & $38.9 \pm 6$ & $36.4 \pm 7$ & $35.9 \pm 6$ & $\mathrm{~T}=0.001$ \\
\hline & HP-P & $38.0 \pm 8$ & $37.1 \pm 8$ & $36.8 \pm 8$ & $\mathrm{~T} \times \mathrm{D}=0.93$ \\
\hline & $\mathrm{HC}$ & $37.7 \pm 8$ & $36.2 \pm 8$ & $35.6 \pm 8$ & $\mathrm{~T} \times \mathrm{S}=0.53$ \\
\hline & $\mathrm{HP}$ & $38.6 \pm 6$ & $36.6 \pm 7$ & $36.2 \pm 8$ & $\mathrm{~T} \times \mathrm{D} \times \mathrm{S}=0.19$ \\
\hline & $\overline{\mathrm{GCM}}$ & $38.3 \pm 6$ & $36.3 \pm 7$ & $35.8 \pm 7$ & \\
\hline & P & $37.9 \pm 8$ & $36.5 \pm 8$ & $35.9 \pm 8$ & \\
\hline & $\overline{\text { Mean }}$ & $38.1 \pm 7$ & $36.4 \pm 8+$ & $35.9 \pm 7 \dagger$ & \\
\hline \multirow{9}{*}{$\begin{array}{l}\text { FFM } \\
(\mathrm{kg})\end{array}$} & HC-GCM & $44.4 \pm 7$ & $44.7 \pm 8$ & $45.5 \pm 8$ & $D=0.74$ \\
\hline & HC-P & $42.8 \pm 6$ & $42.8 \pm 7$ & $42.8 \pm 6$ & $S=0.45$ \\
\hline & HP-GCM & $45.7 \pm 7$ & $45.5 \pm 7$ & $45.8 \pm 8$ & $T=0.57$ \\
\hline & HP-P & $44.5 \pm 7$ & $42.9 \pm 6$ & $43.8 \pm 7$ & $T \times D=0.09$ \\
\hline & $\mathrm{HC}$ & $43.5 \pm 7$ & $43.6 \pm 7$ & $44.0 \pm 7$ & $\mathrm{~T} \times \mathrm{S}=0.12$ \\
\hline & $\mathrm{HP}$ & $45.3 \pm 7$ & $44.6 \pm 6$ & $45.1 \pm 7$ & $\mathrm{~T} \times \mathrm{D} \times \mathrm{S}=0.77$ \\
\hline & $\overline{G C M}$ & $45.2 \pm 7$ & $45.1 \pm 7$ & $45.6 \pm 8$ & \\
\hline & P & $43.4 \pm 6$ & $42.9 \pm 6$ & $43.2 \pm 6$ & \\
\hline & Mean & $44.3 \pm 7$ & $44.1 \pm 7$ & $44.5 \pm 7$ & \\
\hline \multirow{9}{*}{$\begin{array}{l}\text { Body Fat } \\
(\%)\end{array}$} & HC-GCM & $45.7 \pm 3$ & $44.6 \pm 3$ & $43.9 \pm 3$ & $D=0.98$ \\
\hline & HC-P & $46.7 \pm 4$ & $45.5 \pm 4$ & $45.0 \pm 3$ & $S=0.41$ \\
\hline & HP-GCM & $46.0 \pm 3$ & $44.3 \pm 3$ & $43.9 \pm 3$ & $\mathrm{~T}=0.001$ \\
\hline & HP-P & $45.8 \pm 2$ & $46.1 \pm 3$ & $45.4 \pm 2$ & $\mathrm{~T} \times \mathrm{D}=0.46$ \\
\hline & $\mathrm{HC}$ & $46.3 \pm 4$ & $45.1 \pm 4$ & $44.5 \pm 3$ & $\mathrm{~T} \times \mathrm{S}=0.21$ \\
\hline & $\mathrm{HP}$ & $45.9 \pm 2$ & $44.9 \pm 2$ & $44.4 \pm 3$ & $\mathrm{~T} \times \mathrm{D} \times \mathrm{S}=0.25$ \\
\hline & GCM & $45.9 \pm 3$ & $44.4 \pm 3$ & $43.9 \pm 3$ & \\
\hline & $\mathrm{P}$ & $46.4 \pm 4$ & $45.7 \pm 4$ & $45.1 \pm 4$ & \\
\hline & Mean & $46.1 \pm 3$ & $45.0 \pm 3+$ & $44.5 \pm 3+$ & \\
\hline \multirow{9}{*}{$\begin{array}{l}\text { REE } \\
\text { (kcals/d) }\end{array}$} & HC-GCM & $1,548 \pm 262$ & - & $1,453 \pm 302$ & $D=0.73$ \\
\hline & HC-P & $1,400 \pm 180$ & - & $1,388 \pm 218$ & $S=0.35$ \\
\hline & HP-GCM & $1,517 \pm 301$ & - & $1,519 \pm 310$ & $\mathrm{~T}=0.26$ \\
\hline & HP-P & $1,477 \pm 301$ & - & $1,410 \pm 147$ & $\mathrm{~T} \times \mathrm{D}=0.78$ \\
\hline & $\overline{\mathrm{HC}}$ & $1,465 \pm 225$ & - & $1,416 \pm 251$ & $\mathrm{~T} \times \mathrm{S}=0.93$ \\
\hline & $\mathrm{HP}$ & $1,504 \pm 289$ & - & $1,485 \pm 268$ & $\mathrm{~T} \times \mathrm{D} \times \mathrm{S}=0.32$ \\
\hline & $\overline{G C M}$ & $1,530 \pm 276$ & - & $1,490 \pm 298$ & \\
\hline & $P$ & $1,424 \pm 213$ & - & $1,394 \pm 193$ & \\
\hline & $\overline{\text { Mean }}$ & $1,482 \pm 251$ & - & $1,447 \pm 257$ & \\
\hline
\end{tabular}

Data are means \pm standard deviations. $\mathrm{HC}=$ high carbohydrate diet, $\mathrm{HP}=$ high protein diet, $\mathrm{GCM}=$ glucosamine/chondroitin/MSM group, $\mathrm{P}=$ placebo group, $\mathrm{FFM}=$ fat free mass, $\mathrm{REE}=$ resting energy expenditure, $\mathrm{D}=$ diet, $\mathrm{S}=$ supplement, $\mathrm{T}=$ time. + Indicates $\mathrm{p}<0.05$ difference from baseline. 


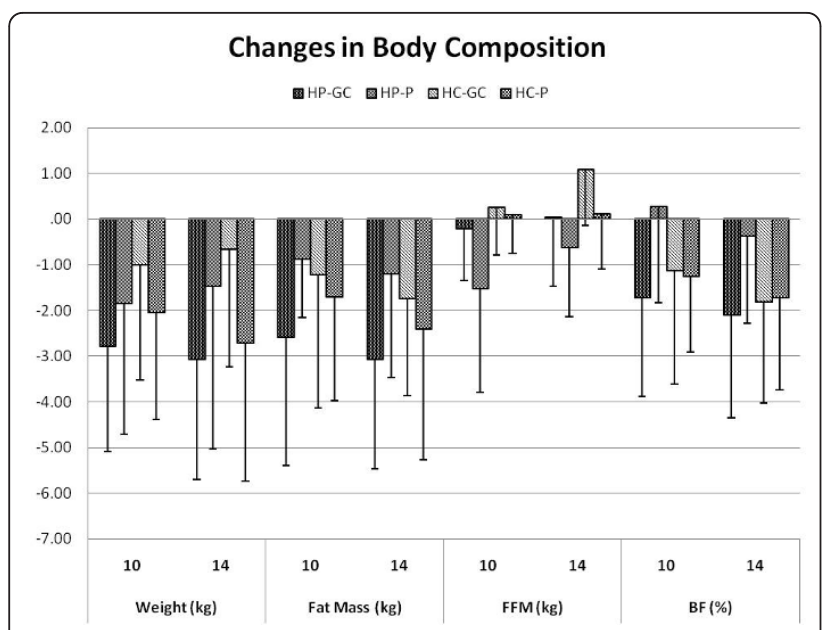

Figure 2 Changes in body composition variables among groups after 10 and 14 weeks of dieting and training.

$(-14 \%)$, creatinine $(-15 \%)$, uric acid $(-9 \%)$, alanine aminotransaminase $(-23 \%), \mathrm{HOMA}_{\mathrm{IR}}(-17 \%)$, and leptin $(-30 \%)$ values while glucose $(-7 \%)$ values tended to be lower. As expected, training moderately increased creatine kinase levels $(49 \%)$ and tended to increase C-reactive protein values (44\%). No significant differences were observed remaining whole blood and serum markers assayed.

\section{Psychosocial and pain questionnaires}

Table 8 presents WOMAC, VAS, and QOL results observed. No significant group or group $\times$ time interactions were observed among groups. Therefore, data are presented for mean time effects. Participants experienced significant reductions in WOMAC perceptions of pain $(-53 \%)$, joint stiffness $(-44 \%)$, and limitations in physical function $(-49 \%)$ during the course of the study with no group or group $\times$ time interactions observed. Likewise, VAS pain was decreased by $59 \%$ during the course of the study. Trends were observed in time by diet $(\mathrm{p}=0.10)$ and time $\times$ supplement $(\mathrm{p}=0.08)$ interactions with a moderate to large effect size observed $(\mathrm{d}=1.1)$ but results were too inconsistent to support claims that GCM supplementation lessens perceptions of knee pain in active individuals. Participants also experienced significant improvements in QOL measures of physical functioning (59\%), vitality (120\%), and social function $(66 \%)$ with no significant differences observed among diet and supplement groups.

\section{Discussion}

Osteoarthritis is a degenerative disease that is characterized by focal erosive lesions, cartilage destruction, subchondral sclerosis, cyst formation, and large osteophyte formation at joint margins that result in the structural and functional failure of synovial joints $[13,40]$. It is the most prevalent musculoskeletal disorder diagnosed in the United States which affects nearly 15\% of Americans and costs an estimated $\$ 80$ billion dollars annually [41]. Athletes with prior knee injuries and individuals who maintain an active lifestyle as they age are also at risk to experience knee pain or degenerative joint issues $[5,27,28]$. Although the etiology of OA involves multiple factors, obesity has been identified as a primary risk factor involved in the development of the disease [9]. Individuals with a BMI greater than $30 \mathrm{~kg} / \mathrm{m}^{2}$ are four times as likely to have knee OA than those with a BMI less than $25.0 \mathrm{~kg} / \mathrm{m}^{2}$ [9]. Although the specific amount of weight loss needed to improve or prevent OA has yet to be determined, empirical research has found that for every one pound of weight loss, there is a four pound reduction in knee joint load per step [42]. With such a drastic reduction in pressure on OA affected knees, alleviating obesity through weight loss has been suggested to be among the most beneficial methods of relieving pressure on osteoarthritic joints.

Participation in a therapeutic exercise program has been reported to aid in the management of OA symptoms $[12,43,44]$. The American College of Sports Medicine recommends that $\mathrm{OA}$ patients engaged in daily static stretching exercises to improve flexibility; low intensity resistance training involving major muscle

Table 3 Knee range of motion data and circumference data for the diet and supplement groups

\begin{tabular}{|c|c|c|c|c|c|c|}
\hline Variable & 0 & $\begin{array}{c}\text { Weeks } \\
10\end{array}$ & 14 & Group & $\begin{array}{l}\text { p-level } \\
\text { Time }\end{array}$ & $\mathbf{G} \times \mathbf{T}$ \\
\hline \multicolumn{7}{|l|}{ Range of Motion } \\
\hline Extension - RL (deg) & $3.02 \pm 2.6$ & $4.20 \pm 3.0$ & $4.05 \pm 3.1$ & 0.12 & 0.13 & 0.56 \\
\hline Extension - LL (deg) & $3.02 \pm 2.6$ & $4.34 \pm 3.2+$ & $4.11 \pm 3.2$ & 0.66 & 0.06 & 0.35 \\
\hline Flexion - RL (deg) & $123.9 \pm 7$ & $125.2 \pm 7$ & $121.6 \pm 8$ & 0.33 & 0.34 & 0.07 \\
\hline Flexion - LL (deg) & $121.2 \pm 8$ & $126.3 \pm 6+$ & $126.7 \pm 8+$ & 0.80 & 0.001 & 0.33 \\
\hline \multicolumn{7}{|l|}{ Circumference } \\
\hline Right Knee (cm) & $36.9 \pm 3$ & $36.6 \pm 3$ & $37.8 \pm 5$ & 0.82 & 0.34 & 0.20 \\
\hline Left Knee (cm) & $36.6 \pm 4$ & $36.6 \pm 3$ & $39.1 \pm 5$ & 0.92 & 0.06 & 0.18 \\
\hline
\end{tabular}

Data are means \pm standard deviations for time main effects. $\mathrm{LL}=$ right leg, $\mathrm{LL}=$ left leg, $\mathrm{G}=$ group, $\mathrm{T}=$ time. $\dagger$ Indicates $\mathrm{p}<0.05$ difference from baseline. 
Table 4 Exercise performance related data for the diet and supplemented groups

\begin{tabular}{|c|c|c|c|c|c|}
\hline Variable & Group & 0 & $\begin{array}{c}\text { Week } \\
10\end{array}$ & 14 & p-value \\
\hline Peak $\mathrm{VO}_{2}$ & HC-GCM & $19.4 \pm 3$ & $19.9 \pm 4$ & $20.5 \pm 3+$ & $D=0.85$ \\
\hline \multirow[t]{8}{*}{$(\mathrm{ml} / \mathrm{kg} / \mathrm{min})$} & HC-P & $18.3 \pm 5$ & $18.5 \pm 6$ & $19.6 \pm 4 \dagger$ & $S=0.20$ \\
\hline & HP-GCM & $20.2 \pm 4$ & $21.4 \pm 4$ & $21.9 \pm 3 t^{*}$ & $\mathrm{~T}=0.05$ \\
\hline & HP-P & $18.7 \pm 4$ & $18.8 \pm 2$ & $16.9 \pm 3 t^{*}$ & $T \times D=0.03$ \\
\hline & $\mathrm{HC}$ & $18.8 \pm 4$ & $19.1 \pm 5$ & $20.0 \pm 4 \dagger$ & $\mathrm{T} \times \mathrm{S}=0.008$ \\
\hline & $\mathrm{HP}$ & $19.8 \pm 4$ & $20.6 \pm 4 t^{*}$ & $20.3 \pm 4 \dagger$ & $\mathrm{T} \times \mathrm{D} \times \mathrm{S}=0.003$ \\
\hline & GCM & $19.9 \pm 3$ & $20.8 \pm 4 t^{*}$ & $21.3 \pm 3 t^{*}$ & \\
\hline & P & $18.4 \pm 5$ & $18.6 \pm 5$ & $18.8 \pm 4$ & \\
\hline & Mean & $19.2 \pm 4$ & $19.8 \pm 4$ & $20.1 \pm 4 \dagger$ & \\
\hline Bench Press & HC-GCM & $26.9 \pm 5$ & $29.1 \pm 8$ & $29.8 \pm 8$ & $D=0.57$ \\
\hline \multirow[t]{8}{*}{$1 \mathrm{RM}(\mathrm{kg})$} & HC-P & $27.0 \pm 7$ & $28.2 \pm 6$ & $29.5 \pm 6$ & $S=0.19$ \\
\hline & HP-GCM & $29.8 \pm 6$ & $33.8 \pm 7$ & $34.6 \pm 6$ & $\mathrm{~T}=0.001$ \\
\hline & HP-P & $24.4 \pm 2$ & $28.4 \pm 3$ & $27.8 \pm 5$ & $T \times D=0.18_{q}$ \\
\hline & $\overline{\mathrm{HC}}$ & $27.0 \pm 6$ & $28.7 \pm 7$ & $29.7 \pm 7$ & $\mathrm{~T} \times \mathrm{S}=0.57$ \\
\hline & $\mathrm{HP}$ & $28.1 \pm 5$ & $32.1 \pm 6$ & $32.5 \pm 6$ & $\mathrm{~T} \times \mathrm{D} \times \mathrm{S}=0.75$ \\
\hline & GCM & $28.5 \pm 6$ & $31.8 \pm 7$ & $32.5 \pm 7$ & \\
\hline & P & $26.2 \pm 6$ & $28.7 \pm 7$ & $29.0 \pm 6$ & \\
\hline & Mean & $27.5 \pm 6$ & $30.2 \pm 6 \dagger$ & $30.9 \pm 7 \dagger$ & \\
\hline \multirow[t]{9}{*}{ Upper Body Endurance (kg) } & HC-GCM & $206 \pm 52$ & $269 \pm 121$ & $245 \pm 120$ & $\mathrm{D}=0.81$ \\
\hline & HC-P & $164 \pm 88$ & $175 \pm 109$ & $198 \pm 142$ & $S=0.02$ \\
\hline & HP-GCM & $242 \pm 81$ & $299 \pm 128$ & $278 \pm 116$ & $T=0.04_{q}$ \\
\hline & $\mathrm{HP}-\mathrm{P}$ & $157 \pm 22$ & $179 \pm 34$ & $153 \pm 26$ & $\mathrm{~T} \times \mathrm{D}=0.59$ \\
\hline & $\overline{\mathrm{HC}}$ & $182 \pm 75$ & $216 \pm 120$ & $219 \pm 131$ & $\mathrm{~T} \times \mathrm{S}=0.17_{\mathrm{q}}$ \\
\hline & HP & $216 \pm 66$ & $262 \pm 120$ & $240 \pm 113$ & $T \times D \times S=0.64$ \\
\hline & GCM & $226 \pm 59$ & $286 \pm 122$ & $264 \pm 115$ & \\
\hline & P & $162 \pm 73$ & $176 \pm 90$ & $184 \pm 119$ & \\
\hline & Mean & $197 \pm 72$ & $237 \pm 120 \dagger$ & $228 \pm 121$ & \\
\hline
\end{tabular}

Data are means \pm standard deviations. $\mathrm{HC}=$ high carbohydrate, $\mathrm{HP}=$ high protein, $\mathrm{GCM}=$ glucosamine/chondroitin/MSM, $\mathrm{P}=$ placebo, $\mathrm{HR}=$ heart rate, $\mathrm{SBP}=$ systolic blood pressure, $\mathrm{DBP}=$ diastolic blood pressure, $\mathrm{VO}_{2}=$ oxygen uptake, $1 \mathrm{RM}=$ one repetition maximum, $\mathrm{D}=$ diet, $\mathrm{S}=$ supplement, $\mathrm{T}=$ time, $\mathrm{q}=$ quadratic alpha level. + Indicates $p<0.05$ difference from baseline. * represents $p<0.05$ difference between groups.

groups (10-12 repetitions, $40-60 \%$ of $1 \mathrm{RM}, 2-3 \mathrm{~d} /$ week); and, aerobic exercise (40-60\% of peak $\mathrm{VO}_{2}$, up to 30 min, 3-5 d/week) as tolerated $[45,46]$. Regular exercise has also been reported to improve the balance and functionality of overweight and obese individuals with knee OA [8]. Therefore, exercise and weight loss have been recommended as effective strategies in managing symptoms of OA $[8-10,12,13,42,43,47]$.

A number of studies support these recommendations. For example, Felson and colleagues [7] reported that weight loss reduced the risk for development of OA in women. Christensen and associates [10] reported that OA patients following a low-energy diet $(\sim 840 \mathrm{kcal} / \mathrm{d})$ that included weekly dietary counseling sessions was more effective in promoting weight loss (11.1\% vs. $4.3 \%)$ and improving WOMAC index scores (-35\% vs. -14\%) than patients educated about weight loss who maintained a moderately hypo-energetic diet $(\sim 1,200 \mathrm{kcal} / \mathrm{d})$. Similarly, Miller and coworkers [9] reported that older obese adults with symptomatic knee OA who followed an intensive weight loss program for 6-months that included meal replacement bars and drinks $(\sim 1,000 \mathrm{kcal} / \mathrm{d})$ experienced greater weight loss $(0.1 \%$ vs. $8.5 \%)$, fat loss $(0.08 \%$ vs. $23.2 \%)$; and, improvement in WOMAC scores $(-5 \%$ vs. $-33 \%)$, 6-min walking distance $(2.3 \%$ vs. $16.7 \%)$, and stair climb time $(7.5 \%$ vs. $-16.3 \%)$ than those who maintained weight. Penninx and associates [47] reported that aerobic and resistance exercise may reduce and/or prevent the incidence of disability in activities of daily living in patients with knee OA. Finally, Messier and coworkers [8] examined the effects of long-term weight loss and exercise on self-reported physical function in older obese adults with knee OA. Participants followed a diet program, an exercise program that involved aerobic and resistance-exercise, a diet plus exercise intervention, or usual care. The researchers found that participants following the diet plus exercise program experienced significant improvements in self-reported physical function, 
Table 5 Mean isokinetic knee extension and flexion data observed over time

\begin{tabular}{|c|c|c|c|c|c|c|}
\hline Variable & 0 & $\begin{array}{c}\text { Weeks } \\
10\end{array}$ & 14 & Group & $\begin{array}{c}\text { p-level } \\
\text { Time }\end{array}$ & $G \times T$ \\
\hline \multicolumn{7}{|l|}{5 Repetitions at $60 \mathrm{deg} / \mathrm{sec}$} \\
\hline Peak Torque - RL Extension (kg/m) & $9.90 \pm 2.0$ & $10.38 \pm 2.6$ & $10.69 \pm 2.8$ & 0.36 & 0.13 & 0.69 \\
\hline Peak Torque - LL Extension (kg/m) & $9.15 \pm 2.2$ & $10.38 \pm 2.6+$ & $10.34 \pm 2.9+$ & 0.47 & 0.04 & 0.44 \\
\hline Peak Torque - RL Flexion (kg/m) & $4.66 \pm 1.6$ & $5.53 \pm 1.6 \dagger$ & $5.99 \pm 2.1 \dagger$ & 0.62 & 0.003 & 0.90 \\
\hline Peak Torque - LL Flexion (kg/m) & $4.44 \pm 1.6$ & $5.47 \pm 1.7 \dagger$ & $5.61 \pm 1.9 \dagger$ & 0.71 & 0.01 & 0.45 \\
\hline Fatigue Index - RL Extension (\%) & $-0.8 \pm 50$ & $9.4 \pm 18$ & $8.7 \pm 25$ & 0.79 & 0.32 & 0.54 \\
\hline Fatigue Index - LL Extension (\%) & $3.5 \pm 30$ & $11.1 \pm 19$ & $11.0 \pm 18$ & 0.73 & 0.38 & 0.41 \\
\hline Fatigue Index - RL Flexion (\%) & $-8.8 \pm 72$ & $16.9 \pm 28 \dagger$ & $25.3 \pm 13+$ & 0.23 & 0.02 & 0.28 \\
\hline Fatigue Index - LL Flexion (\%) & $12.6 \pm 30$ & $19.4 \pm 18$ & $23.4 \pm 10$ & 0.82 & 0.12 & 0.75 \\
\hline \multicolumn{7}{|l|}{10 Repetitions at $180 \mathrm{deg} / \mathrm{sec}$} \\
\hline Peak Torque - RL Extension (kg/m) & $6.05 \pm 2.3$ & $6.45 \pm 2.4$ & $6.82 \pm 2.4 \dagger$ & 0.12 & 0.05 & 0.40 \\
\hline Peak Torque - LL Extension (kg/m) & $5.60 \pm 2.8$ & $6.40 \pm 2.7$ & $6.85 \pm 2.3 \dagger$ & 0.47 & 0.04 & 0.44 \\
\hline Peak Torque - RL Flexion (kg/m) & $2.80 \pm 1.5$ & $3.70 \pm 1.8 \dagger$ & $4.10 \pm 1.9 \dagger$ & 0.35 & 0.001 & 0.66 \\
\hline Peak Torque - LL Flexion (kg/m) & $2.68 \pm 1.7$ & $3.49 \pm 1.6+$ & $3.90 \pm 1.7 \dagger$ & 0.60 & 0.001 & 0.48 \\
\hline Fatigue Index - RL Extension (\%) & $-1.9 \pm 33$ & $-9.6 \pm 67$ & $9.5 \pm 26$ & 0.19 & 0.12 & 0.84 \\
\hline Fatigue Index - LL Extension (\%) & $-17.6 \pm 55$ & $5.2 \pm 27 \dagger$ & $-0.2 \pm 47 \dagger$ & 0.08 & 0.02 & 0.49 \\
\hline Fatigue Index - RL Flexion (\%) & $-12.1 \pm 84$ & $7.9 \pm 56+$ & $17.7 \pm 22 \dagger$ & 0.37 & 0.08 & 0.53 \\
\hline Fatigue Index - LL Flexion (\%) & $-48.9 \pm 139$ & $9.8 \pm 53+$ & $9.7 \pm 67 \dagger$ & 0.61 & 0.02 & 0.44 \\
\hline \multicolumn{7}{|l|}{15 Repetitions at $300 \mathrm{deg} / \mathrm{sec}$} \\
\hline Peak Torque - RL Extension (kg/m) & $32.6 \pm 13$ & $36.6 \pm 14$ & $36.2 \pm 15$ & 0.68 & 0.17 & 0.39 \\
\hline Peak Torque - LL Extension (kg/m) & $31.0 \pm 16$ & $36.2 \pm 15 \dagger$ & $37.0 \pm 15 \dagger$ & 0.62 & 0.02 & 0.12 \\
\hline Peak Torque - RL Flexion (kg/m) & $14.8 \pm 11$ & $19.0 \pm 13 \dagger$ & $19.3 \pm 13 \dagger$ & 0.76 & 0.02 & 0.61 \\
\hline Peak Torque - LL Flexion (kg/m) & $12.7 \pm 11$ & $17.2 \pm 12+$ & $17.6 \pm 11 \dagger$ & 0.82 & 0.02 & 0.24 \\
\hline Fatigue Index - RL Extension (\%) & $7.8 \pm 43$ & $10.8 \pm 27$ & $17.2 \pm 29$ & 0.46 & 0.19 & 0.83 \\
\hline Fatigue Index - LL Extension (\%) & $4.0 \pm 48$ & $11.3 \pm 24$ & $17.6 \pm 37$ & 0.46 & 0.25 & 0.77 \\
\hline Fatigue Index - RL Flexion (\%) & $-2.0 \pm 94$ & $14.1 \pm 70$ & $17.9 \pm 68+$ & 0.52 & 0.36 & 0.82 \\
\hline Fatigue Index - LL Flexion (\%) & $-20.2 \pm 103$ & $16.3 \pm 89+$ & $19.1 \pm 62 \dagger$ & 0.76 & 0.02 & 0.94 \\
\hline
\end{tabular}

Data are means \pm standard deviations for time main effects. $\mathrm{RL}=$ right leg, $\mathrm{LL}=$ left leg, $\mathrm{G}=$ group, $\mathrm{T}=$ time. $\dagger$ Indicates $\mathrm{p}<0.05$ difference from baseline.

6-min walk distance, stair climb time, and knee pain compared to those in the usual care group. Exercise alone improved 6-min walk distance while dieting alone did not result in greater functional improvement than usual care.

Present findings support prior reports indicating that weight loss and exercise training provided therapeutic benefit for women with knee OA. In this regard, the circuit style resistance-training program and weight loss program used in this study promoted significant reductions in body mass $(-2.4 \%)$, fat mass $(-6 \%)$, and body fat $(-3.5 \%)$ while increasing symptom-limited peak $\mathrm{VO}_{2}$ (5\%), upper body $1 \mathrm{RM}$ strength (12\%), upper body muscular endurance (20\%), isokinetic knee extension and flexion peak torque (12-46\%), step up and over knee function (8-15\%), and forward lunge knee function (7-20\%). These changes were accompanied by significant improvements in total cholesterol (-8\%), low-density lipoproteins $(-12 \%), \mathrm{HOMA}_{\mathrm{IR}}(-17 \%)$, and leptin $(-30 \%)$ values. Interestingly, reductions in serum leptin levels have been reported to be associated with improved physical function in patients with OA [48]. Participants also reported less perceptions of pain (-53\%), joint stiffness $(-44 \%)$, and limitations in physical function $(-49 \%)$ on the WOMAC index as well as a 59\% reduction in VAS pain ratings. These findings provide additional evidence that patients with knee OA may experience significant improvements in markers of health, fitness, functional capacity, and perceptions of pain when following a weight loss and exercise program that includes resistance-training.

However, present findings add to our understanding of how different types of diets and concomitant dietary supplementation with a GCM affect weight loss, training adaptations, functional capacity, and/or perceptions of pain in women with knee OA. In this regard, a number of studies have indicated that replacing carbohydrate with protein while following a hypo-energetic diet promotes greater fat loss $[14,15,19,49]$. The rationale has been that there are thermogenic advantages in metabolizing protein compared to carbohydrate and that a higher amount of protein in the diet can help maintain fat free 
Table 6 Functional balance testing results observed over time

\begin{tabular}{|c|c|c|c|c|c|c|}
\hline Variable & 0 & $\begin{array}{c}\text { Weeks } \\
10\end{array}$ & 14 & Group & $\begin{array}{c}\text { p-level } \\
\text { Time }\end{array}$ & $\mathrm{G} \times \mathrm{T}$ \\
\hline \multicolumn{7}{|l|}{ Sit to Stand Function } \\
\hline Weight Transfer (sec) & $0.377 \pm 0.18$ & $0.355 \pm 0.17$ & $0.370 \pm 0.22$ & 0.80 & 0.91 & 0.89 \\
\hline Rising Index (\% body weight) & $16.6 \pm 4.3$ & $18.6 \pm 5.7$ & $18.2 \pm 5.6$ & 0.97 & 0.13 & 0.34 \\
\hline Sway Velocity (deg/sec) & $4.63 \pm 1.3$ & $4.56 \pm 1.1$ & $4.62 \pm 1.2$ & 0.78 & 0.78 & 0.12 \\
\hline \multicolumn{7}{|l|}{ Step Up and Over Knee Function } \\
\hline Lift-up Index - RL (\% body weight) & $41.2 \pm 9.2$ & $43.6 \pm 9.7$ & $44.5 \pm 8.6+$ & 0.90 & 0.01 & 0.71 \\
\hline Lift-up Index - LL (\% body weight) & $34.7 \pm 8.5$ & $37.4 \pm 8.1$ & $38.9 \pm 7.2 \dagger$ & 0.70 & 0.002 & 0.50 \\
\hline Impact Index - RL (\% body weight) & $48.7 \pm 11.2$ & $48.4 \pm 12.1$ & $48.3 \pm 10.9$ & 0.91 & 0.70 & 0.77 \\
\hline Impact Index - LL (\% body weight) & $52.1 \pm 10.6$ & $52.4 \pm 13.5$ & $54.5 \pm 14.1$ & 0.84 & 0.22 & 0.47 \\
\hline Movement Time - RL (sec) & $1.73 \pm 0.3$ & $1.55 \pm 0.2 \dagger$ & $1.47 \pm 0.2 \dagger$ & 0.83 & 0.001 & 0.07 \\
\hline Movement Time - LL (sec) & $1.76 \pm 0.3$ & $1.60 \pm 0.5 \dagger$ & $1.49 \pm 0.3 \dagger$ & 0.98 & 0.002 & 0.68 \\
\hline \multicolumn{7}{|l|}{ Forward Lunge Knee Function } \\
\hline Distance - RL (\% body height) & $43.2 \pm 7$ & $45.6 \pm 7+$ & $46.3 \pm 7 \dagger$ & 0.14 & 0.001 & 0.75 \\
\hline Distance - LL (\% body height) & $42.5 \pm 5$ & $45.7 \pm 7 \dagger$ & $46.2 \pm 7 \dagger$ & 0.24 & 0.001 & 0.49 \\
\hline Impact Index - RL (\% body weight) & $18.5 \pm 5$ & $19.0 \pm 7$ & $18.6 \pm 5$ & 0.65 & 0.76 & 0.77 \\
\hline Impact Index - LL (\% body weight) & $14.0 \pm 5$ & $16.4 \pm 7$ & $15.7 \pm 5$ & 0.86 & 0.15 & 0.97 \\
\hline Contact Time - RL (sec) & $1.664 \pm 0.5$ & $1.344 \pm 0.3 \dagger$ & $1.359 \pm 0.4 \dagger$ & 0.57 & 0.001 & 0.81 \\
\hline Contact Time - LL (sec) & $1.641 \pm 0.7$ & $1.347 \pm 0.4 \dagger$ & $1.310 \pm 0.4 \dagger$ & 0.64 & 0.002 & 0.98 \\
\hline Force Impulse - RL (\% body weight/sec) & $168 \pm 53$ & $139 \pm 36+$ & $141 \pm 38+$ & 0.61 & 0.001 & 0.59 \\
\hline Force Impulse - LL (\% body weight/sec) & $162 \pm 65$ & $136 \pm 33 \dagger$ & $132 \pm 37 \dagger$ & 0.62 & 0.002 & 0.99 \\
\hline
\end{tabular}

Data are means \pm standard deviations for time main effects. $R L=$ right leg, $L L=$ left leg, $G=$ group, $T=$ time. $\dagger$ Indicates $p<0.05$ difference from baseline.

mass during weight loss thereby helping minimize reductions in resting energy expenditure that is often associated with weight loss $[14,16]$. Our previous research examining the efficacy of the exercise and diet program used in this study provides some support to this theory $[20,21,23]$. Therefore, we hypothesized that women with knee OA may experience greater weight loss and therapeutic benefits from following a higher protein diet. Present findings, however, indicate that women with knee OA benefited from both a higher carbohydrate and higher protein diet. Although there was some evidence that women following the HP diet experienced greater gains in symptom-limited peak aerobic capacity, no significant differences were observed in amount of weight loss, fat loss, or resting energy expenditure when diets were compared. Participants in both groups effectively maintained fat free mass and resting energy expenditure levels despite experiencing significant reductions in weight and fat mass. Additionally, no significant differences were observed between diet types among changes in strength, muscular endurance, functional tests, or markers of health. These findings indicate that the type of diet does not appear to influence weight loss or training adaptations in sedentary obese women with knee OA initiating a weight loss and exercise training program. The lack of statistical significance could be due to the small sample-size studied and/or that the exercise stimulus was effective enough to negate any additional metabolic benefits from adherence to a higher protein diet in this population. Nevertheless, present findings do not support our hypothesis that women with knee OA may experience greater benefits from following a higher protein hypo-energetic diet.

Several studies have also indicated that glucosamine and/or chondroitin supplementation may provide therapeutic benefits in individuals with knee OA. For example, Reginster and associates [50] reported that 3-years of glucosamine sulphate supplementation $(1,500 \mathrm{mg} / \mathrm{d})$ prevented progression of joint-space narrowing and improved WOMAC scores in patients with knee OA. Similarly, Pavelka and colleagues [25] found that dietary supplementation of glucosamine sulfate $(1,500 \mathrm{mg} / \mathrm{d}$ for 3 -years) retarded the clinical progression of knee OA. Braham et al [51] found that 2,000 $\mathrm{mg} / \mathrm{d}$ of glucosamine supplementation for 12-weeks improved markers of quality of life and self-reported perceptions of knee pain in individuals with regular knee pain. Usha and coworkers [26] reported that dietary supplementation of $1,500 \mathrm{mg} / \mathrm{d}$ of glucosamine and/or MSM for 12-weeks produced an analgesic and anti-inflammatory effect, reduced perceptions of pain, and improved functional ability of joints in patients with mild to moderate knee OA. Moreover, Matsuno and colleagues [52] investigated the effects of 12-weeks of ingesting a dietary supplement containing glucosamine hydrochloride $(1,200 \mathrm{mg} / \mathrm{d})$, shark cartiliage powder $(300 \mathrm{mg} / \mathrm{d})$, chondroitin $(75-111 \mathrm{mg} / \mathrm{d})$, and 
Table 7 Fasting serum blood and hormone markers observed over time

\begin{tabular}{|c|c|c|c|c|c|c|}
\hline Variable & 0 & $\begin{array}{c}\text { Weeks } \\
10\end{array}$ & 14 & Group & $\begin{array}{c}\text { p-level } \\
\text { Time }\end{array}$ & $G \times T$ \\
\hline \multicolumn{7}{|l|}{ Blood Lipids \& Glucose } \\
\hline Triglycerides (mmol/l) & $1.71 \pm 1.0$ & $1.59 \pm 1.0$ & $1.62 \pm 1.0$ & 0.91 & 0.51 & 0.83 \\
\hline Cholesterol (mmol/l) & $5.61 \pm 1.0$ & $5.15 \pm 0.8+$ & $5.25 \pm 1.2$ & 0.05 & $0.08_{q}$ & 0.78 \\
\hline LDL (mmol/l) & $3.65 \pm 0.8$ & $3.23 \pm 0.6+$ & $3.34 \pm 0.9$ & 0.13 & $0.04 \mathrm{q}$ & 0.51 \\
\hline $\mathrm{HDL}(\mathrm{mmol} / \mathrm{l})$ & $1.39 \pm 0.3$ & $1.23 \pm 0.2 \dagger$ & $1.24 \pm 0.3 \dagger$ & 0.14 & 0.02 & 0.96 \\
\hline Glucose $(\mathrm{mmol} / \mathrm{l})$ & $5.93 \pm 0.8$ & $5.69 \pm 0.8$ & $5.52 \pm 0.9$ & 0.99 & 0.08 & 0.96 \\
\hline \multicolumn{7}{|l|}{ Serum Protein and Enzymes } \\
\hline BUN $(\mathrm{mmol} / \mathrm{l})$ & $5.09 \pm 1.4$ & $4.85 \pm 1.4$ & $4.36 \pm 1.4 \dagger$ & 0.91 & 0.006 & 0.44 \\
\hline Creatinine (1/2 mol/l) & $72 \pm 15$ & $69 \pm 13$ & $61 \pm 15 \dagger$ & 0.66 & 0.003 & 0.68 \\
\hline BUN/Creatinine Ratio & $17.6 \pm 3.8$ & $17.6 \pm 3.7$ & $18.0 \pm 4.4$ & 0.63 & 0.55 & 0.33 \\
\hline Uric Acid (1/2 mol/l) & $328 \pm 92$ & $300 \pm 68+$ & $300 \pm 77 \dagger$ & 0.49 & 0.09 & 0.93 \\
\hline CK (IU/I) & $59 \pm 36$ & $87 \pm 42 \dagger$ & $88 \pm 27 \dagger$ & 0.23 & 0.001 & 0.86 \\
\hline ALT (IU/I) & $25.5 \pm 11$ & $19.7 \pm 6+$ & $22.0 \pm 10$ & 0.81 & $0.008_{q}$ & 0.14 \\
\hline AST (IU/I) & $20.0 \pm 6$ & $20.0 \pm 5$ & $21.8 \pm 8$ & 0.95 & 0.17 & 0.96 \\
\hline GGT (IU/I) & $42.8 \pm 30$ & $41.7 \pm 32$ & $50.9 \pm 45$ & 0.66 & 0.15 & 0.23 \\
\hline \multicolumn{7}{|l|}{ Hormones } \\
\hline C-Reactive Protein $(1 / 2 \mathrm{~mol} / \mathrm{l})$ & $4.93 \pm 4.3$ & $5.12 \pm 4.2$ & $7.12 \pm 6.7+$ & 0.84 & 0.06 & 0.55 \\
\hline IL-6 (pg/ml) & $3.68 \pm 3.9$ & $3.54 \pm 4.1$ & $3.38 \pm 5.0$ & 0.13 & 0.78 & 0.16 \\
\hline TNF- $\alpha(p g / m l)$ & $0.72 \pm 2.9$ & $0.90 \pm 3.5$ & $0.96 \pm 3.3$ & 0.19 & 0.71 & 0.60 \\
\hline Cortisol (nmol/l) & $825 \pm 827$ & $807 \pm 599$ & $846 \pm 943$ & 0.75 & 0.56 & 0.07 \\
\hline Insulin (pmol/l) & $90.7 \pm 90$ & $96 \pm 104$ & $88 \pm 98$ & 0.13 & 0.58 & 0.81 \\
\hline Glucose/Insulin Ratio & $18.3 \pm 20$ & $20.2 \pm 26$ & $24.1 \pm 29$ & 0.36 & 0.38 & 0.67 \\
\hline $\mathrm{HOMA}_{\mathrm{IR}}$ & $3.26 \pm 3.5$ & $3.33 \pm 4.0$ & $2.69 \pm 3.0+$ & 0.07 & 0.05 & 0.42 \\
\hline Leptin (1/2 g/l) & $185 \pm 134$ & $130 \pm 86 \dagger$ & $134 \pm 93+$ & 0.97 & 0.03 & 0.51 \\
\hline
\end{tabular}

Data are means \pm standard deviations for time main effects. $\mathrm{LDL}=$ low density lipoproteins, $\mathrm{HDL}=$ high density lipoproteins, $\mathrm{BUN}=$ blood urea nitrogen, $\mathrm{CK}=$ creatine kinase, ALT = alanine aminotransferase, AST = aspartate aminotranferase, GGT = gamma glutamyltransferase, IL- $6=$ interleukin 6 , TNF- $\alpha=$ tumor necrosis factor alpha, $\mathrm{HOMA}_{\mathrm{IR}}=$ homeostatic model assessment of insulin resistance, $\mathrm{G}=$ group, $\mathrm{T}=$ time, $q=$ quadratic alpha level. + Indicates $p<0.05$ difference from baseline.

quercetin $(45 \mathrm{mg} / \mathrm{d})$ on synovial fluid properties of patients with OA. The researchers reported that the OA patients experienced significant improvements in pain symptoms, ability to perform daily activities (walking and climbing up and down stairs), and changes in synovial fluid properties. Finally, Ng and coworkers [53] reported that dietary supplementation of glucosamine sulphate $(1,500 \mathrm{mg} / \mathrm{d})$ for 6 -weeks reduced OA symptoms in individuals walking a minimum of approximately 30 -min per day. These findings provide support to the theory that glucosamine and chondroitin supplementation may provide some therapeutic benefits to patients with knee OA.

In the present study, subjects ingested in a double blind and randomized manner a placebo or a dietary supplement containing $1,500 \mathrm{mg} / \mathrm{d}$ of glucosamine, $1,200 \mathrm{mg} / \mathrm{d}$ of chondroitin sulfate, and $900 \mathrm{mg} / \mathrm{d}$ of MSM. We found that symptom-limited peak aerobic capacity was increased to a greater degree in participants ingesting the GCM supplement with the greatest effects observed in the HPGCM group. In addition, mean group upper extremity muscular endurance was greater in the GCM group compared to the P group. However, GCM supplementation did not significantly affect remaining markers of isotonic or isokinetic strength, balance, functional capacity, markers of health, self-reported perceptions of pain, or indicators of quality of life. These findings indicate that GCM supplementation provides only marginal additive benefit to a resistance-based exercise and weight loss program. The lack of additive benefits observed could be due to limitations in sample size, length of the intervention, and/or the fact that the exercise intervention resulted in marked improvement in functional capacity and perceptions of pain thereby minimizing the impact of dietary supplementation of GCM. However, additional research is needed to examine the influence of GCM supplementation during a training and weight loss program before definitive conclusions can be drawn.

\section{Conclusions}

Present findings indicate that adherence to a resistancebased circuit training and weight loss program promoted weight and fat loss, increased strength and functional capacity, and improved markers of health in sedentary obese women with clinically-diagnosed knee osteoarthritis. 
Table 8 WOMAC, VAS pain, and quality of life measures observed over time

\begin{tabular}{|c|c|c|c|c|c|c|}
\hline Variable & 0 & $\begin{array}{c}\text { Weeks } \\
10\end{array}$ & 14 & Group & $\begin{array}{c}\text { p-level } \\
\text { Time }\end{array}$ & $G \times T$ \\
\hline \multicolumn{7}{|l|}{ WOMAC } \\
\hline Pain & $156 \pm 81$ & $84 \pm 64 t$ & $74 \pm 58+$ & 0.81 & 0.001 & 0.46 \\
\hline Stiffness & $84 \pm 41$ & $47 \pm 44 \dagger$ & $50 \pm 40 \dagger$ & 0.45 & 0.001 & 0.63 \\
\hline Physical Function & $879 \pm 428$ & $517 \pm 390 \dagger$ & $449 \pm 335 \dagger$ & 0.81 & 0.001 & 0.61 \\
\hline \multicolumn{7}{|l|}{ VAS } \\
\hline Pain & $3.97 \pm 1.9$ & $2.51 \pm 1.8 \dagger$ & $1.78 \pm 1.8 \dagger$ & 0.18 & 0.001 & 0.43 \\
\hline \multicolumn{7}{|l|}{ Quality of Life } \\
\hline Physical Function & $44.4 \pm 38$ & $55.4 \pm 36$ & $70.4 \pm 17 \dagger$ & 0.47 & 0.004 & 0.93 \\
\hline General Health & $13.3 \pm 15$ & $15.2 \pm 10$ & $16.7 \pm 7$ & 0.73 & 0.12 & 0.47 \\
\hline Vitality & $8.3 \pm 12$ & $15.0 \pm 10$ & $18.3 \pm 7+$ & 0.06 & 0.001 & 0.88 \\
\hline Social Function & $18.3 \pm 20$ & $26.4 \pm 14$ & $30.3 \pm 9+$ & 0.21 & 0.004 & 0.13 \\
\hline Mental Health & $11.7 \pm 4$ & $13.5 \pm 2$ & $9.6 \pm 5$ & 0.91 & $0.001_{\mathrm{q}}$ & 0.51 \\
\hline
\end{tabular}

Data are means \pm standard deviations for main time effects. WOMAC $=$ Western Ontario and McMasters University Osteoarthritis Index, VAS $=$ Visual Analogue Scale. + Indicates $p<0.05$ difference from baseline.

These findings support contentions that exercise and weight loss may have therapeutic benefits for women with knee osteoarthritis. Although some trends were observed, the type of diet and dietary supplementation of GCM provided marginal additive benefits. However, since diet and GCM supplementation appeared to affect symptomlimited peak aerobic capacity and some moderate to large effect sizes were noted in key variables, additional research with a larger sample size is needed to determine whether type of diet and/or GCM supplementation while participating in an exercise and weight loss program may provide therapeutic benefits in this population.

\section{Acknowledgements}

We would like to thank the individuals who participated in this study as well as all of the students and administrative support staff's at Baylor University and Texas A\&M University that assisted in conducting this study. We would also like thank Rodney Bowden and Beth Lanning for their input on selecting the QOL questionnaire used in this study; Mike Greenwood for his assistance in overseeing the study and mentoring doctoral students who assisted in this study; and, Dr. Ron Wilson for providing medical supervision for this study.

\section{Author details}

${ }^{1}$ Exercise \& Sport Nutrition Lab, Department of Health \& Kinesiology, Texas A\&M University, College Station, TX 77843-4243, USA. ${ }^{2}$ Human Performance Lab, Exercise \& Sport Science Department, University of Mary-Hardin Baylor, Belton, Texas 76513, USA. ${ }^{3}$ Department of Health, Human Performance and Recreation, Baylor University, One Bear Place, Box 97313, Waco, TX 767987313, USA. ${ }^{4}$ Higuchi Biosciences Center, University of Kansas, Lawrence, KS 66047, USA. ${ }^{5}$ School of Physical Education \& Exercise Science, University of South Florida, Tampa, FL 33620, USA. ${ }^{6}$ Department of Health and Exercise Science, University of Oklahoma, Norman OK 73019, USA. ${ }^{7}$ Quality Improvement Programs, BlueCross and BlueShield of Texas, Dallas, TX 75266, USA. ${ }^{8}$ Bouve College of Health, Northeastern University, Boston, MA 02115, USA. ${ }^{9}$ Department of Health, Exercise Science, and Secondary Education, Lee University, Cleveland, TN 37320 m USA. ${ }^{10}$ Schools of Biomedical \& Health Sciences, Victoria University, Victoria University, Melbourne Victoria 8001, Australia. ${ }^{11}$ Department of Family \& Consumer Sciences, Baylor University, One Bear Place, Box 97346, Waco, TX 76798-73346, USA.

\section{Authors' contributions}

TMC served as the study supervisor, oversaw all testing, and assisted in writing of the manuscript. CW assisted in data collection and manuscript preparation. $C R, M F, L G, B C, C M K, K D, R L, E N, M I$ and $M C$ assisted in data collection, data analysis, and/or manuscript preparation. DW oversaw analysis of blood work. LS provided input on study design and results. RBK served as Principal Investigator and contributed to the design of the study, statistical analysis, manuscript preparation, and procurement of external funding. All authors read and approved the final manuscript.

\section{Competing interests}

Curves International (Waco, TX, USA) provided funding for this project through an unrestricted research grant to Baylor University when the Principal Investigator and the Exercise \& Sport Nutrition Lab were affiliated with that institution and currently provides funding to Texas A\&M University to conduct exercise and nutrition related research. All researchers involved independently collected, analyzed, and interpreted the results from this study and have no financial interests concerning the outcome of this investigation. Data from this study have been presented at the Federation of American Societies of Experimental Biology annual meeting. Publication of these findings should not be viewed as endorsement by the investigators or their institutions of the programs or materials investigated.

Received: 7 March 2011 Accepted: 20 June 2011

Published: 20 June 2011

\section{References}

1. Felson DT, Zhang Y: An update on the epidemiology of knee and hip osteoarthritis with a view to prevention. Arthritis Rheum 1998, 41:1343-1355.

2. Murphy LB, Helmick CG, Schwartz TA, Renner JB, Tudor G, Koch GG, Dragomir AD, Kalsbeek WD, Luta G, Jordan JM: One in four people may develop symptomatic hip osteoarthritis in his or her lifetime. Osteoarthritis Cartilage 2010, 18:1372-1379.

3. Dillon CF, Rasch EK, Gu Q, Hirsch R: Prevalence of knee osteoarthritis in the United States: arthritis data from the Third National Health and Nutrition Examination Survey 1991-94. J Rheumatol 2006, 33:2271-2279.

4. Oliveria SA, Felson DT, Reed JI, Cirillo PA, Walker AM: Incidence of symptomatic hand, hip, and knee osteoarthritis among patients in a health maintenance organization. Arthritis Rheum 1995, 38:1134-1141.

5. Vad V, Hong HM, Zazzali M, Agi N, Basrai D: Exercise recommendations in athletes with early osteoarthritis of the knee. Sports Med 2002, 32:729-739.

6. Felson DT, Niu J, Clancy M, Sack B, Aliabadi P, Zhang Y: Effect of recreational physical activities on the development of knee 
osteoarthritis in older adults of different weights: the Framingham Study. Arthritis Rheum 2007, 57:6-12.

7. Felson DT, Zhang Y, Anthony JM, Naimark A, Anderson JJ: Weight loss reduces the risk for symptomatic knee osteoarthritis in women. The Framingham Study. Ann Intern Med 1992, 116:535-539.

8. Messier SP, Loeser RF, Miller GD, Morgan TM, Rejeski WJ, Sevick MA, Ettinger WH, Pahor M, Williamson JD: Exercise and dietary weight loss in overweight and obese older adults with knee osteoarthritis: the Arthritis, Diet, and Activity Promotion Trial. Arthritis Rheum 2004, 50:1501-1510.

9. Miller GD, Nicklas BJ, Davis C, Loeser RF, Lenchik L, Messier SP: Intensive weight loss program improves physical function in older obese adults with knee osteoarthritis. Obesity (Silver Spring) 2006, 14:1219-1230.

10. Christensen R, Astrup A, Bliddal H: Weight loss: the treatment of choice for knee osteoarthritis? A randomized trial. Osteoarthritis Cartilage 2005, 13:20-27.

11. Slemenda C, Heilman DK, Brandt KD, Katz BP, Mazzuca SA, Braunstein EM, Byrd D: Reduced quadriceps strength relative to body weight: a risk factor for knee osteoarthritis in women? Arthritis Rheum 1998, 41:1951-1959.

12. Hernandez-Molina G, Reichenbach S, Zhang B, Lavalley M, Felson DT: Effect of therapeutic exercise for hip osteoarthritis pain: results of a metaanalysis. Arthritis Rheum 2008, 59:1221-1228.

13. Messier SP: Obesity and osteoarthritis: disease genesis and nonpharmacologic weight management. Rheum Dis Clin North Am 2009, 34:713-729.

14. Devkota S, Layman DK: Protein metabolic roles in treatment of obesity. Curr Opin Clin Nutr Metab Care 2010, 13:403-407.

15. Acheson KJ: Carbohydrate for weight and metabolic control: where do we stand? Nutrition 2010, 26:141-145.

16. Wilborn C, Beckham J, Campbell B, Harvey T, Galbreath M, La Bounty P, Nassar E, Wismann J, Kreider R: Obesity: prevalence, theories, medical consequences, management, and research directions. J Int Soc Sports Nutr 2005, 2:4-31.

17. Te Morenga LA, Levers MT, Williams SM, Brown RC, Mann J: Comparison of high protein and high fiber weight-loss diets in women with risk factors for the metabolic syndrome: a randomized trial. Nutr J 2011, 10:40.

18. Wycherley TP, Noakes M, Clifton PM, Cleanthous X, Keogh JB, Brinkworth GD: A high-protein diet with resistance exercise training improves weight loss and body composition in overweight and obese patients with type 2 diabetes. Diabetes Care 2010, 33:969-976.

19. Clifton PM, Bastiaans K, Keogh JB: High protein diets decrease total and abdominal fat and improve CVD risk profile in overweight and obese men and women with elevated triacylglycerol. Nutr Metab Cardiovasc Dis 2009, 19:548-554.

20. Kerksick C, Thomas A, Campbell B, Taylor L, Wilborn C, Marcello B, Roberts M, Pfau E, Grimstvedt M, Opusunju J, Magrans-Courtney T, Rasmussen C, Wilson R, Kreider RB: Effects of a popular exercise and weight loss program on weight loss, body composition, energy expenditure and health in obese women. Nutr Metab (Lond) 2009, 6:23.

21. Kerksick CM, Wismann-Bunn J, Fogt D, Thomas AR, Taylor L, Campbell BI, Wilborn CD, Harvey T, Roberts MD, La Bounty P, Galbreath M, Marcello B, Rasmussen CJ, Kreider RB: Changes in weight loss, body composition and cardiovascular disease risk after altering macronutrient distributions during a regular exercise program in obese women. Nutr J 2010, 9:59.

22. Kreider RB, Serra M, Beavers KM, Moreillon J, Kresta JY, Byrd M, Oliver JM, Gutierrez J, Hudson G, Deike E, Shelmadine B, Leeke P, Rasmussen C, Greenwood M, Cooke M, Kerksick C, Campbell JK, Beiseigal J, Jonnalagadda SS: A structured diet and exercise program promotes favorable changes in weight loss, body composition, and weight maintenance. Journal of the American Dietetic Association 2011. 111:828-843.

23. Kreider RB, Rasmussen C, Kerksick CM, Wilborn C, Taylor L, Campbell B, Magrans-Courtney T, Fogt D, Ferreira M, Li R, Galbreath M, losia M, Cooke M, Serra M, Gutierrez J, Byrd M, Kresta JY, Simbo S, Oliver J, Greenwood M: A carbohydrate-restricted diet during resistance training promotes more favorable changes in body composition and markers of health in obese women with and without insulin resistance. Physician Sportsmed 2011, 39:1-14.

24. Qiu GX, Gao SN, Giacovelli G, Rovati L, Setnikar I: Efficacy and safety of glucosamine sulfate versus ibuprofen in patients with knee osteoarthritis. Arzneimittelforschung 1998, 48:469-474.
25. Pavelka K, Gatterova J, Olejarova M, Machacek S, Giacovelli G, Rovati LC: Glucosamine sulfate use and delay of progression of knee osteoarthritis: a 3-year, randomized, placebo-controlled, double-blind study. Arch Intern Med 2002, 162:2113-2123.

26. Usha PR, Naidu MU: Randomised, Double-Blind, Parallel, PlaceboControlled Study of Oral Glucosamine, Methylsulfonylmethane and their Combination in Osteoarthritis. Clin Drug Investig 2004, 24:353-363.

27. Petersen SG, Saxne T, Heinegard D, Hansen M, Holm L, Koskinen S, Stordal C, Christensen H, Aagaard P, Kjaer M: Glucosamine but not ibuprofen alters cartilage turnover in osteoarthritis patients in response to physical training. Osteoarthritis Cartilage 2010, 18:34-40.

28. Ostojic SM, Arsic M, Prodanovic S, Vukovic J, Zlatanovic M: Glucosamine administration in athletes: effects on recovery of acute knee injury. Res Sports Med 2007, 15:113-124.

29. Hespel P, Maughan RJ, Greenhaff PL: Dietary supplements for football. J Sports Sci 2006, 24:749-761.

30. Heavin G: Permanent Results Without Permanent Dieting: The Curves for Women Wight Loss Method Waco, TX: Curves Interational Inc; 1999.

31. Almada A, Kreider R: Comparison of the reliability of repeated whole body DEXA scans to repeated spine and hip scans. J Bone Miner Res 1999, 14:S369.

32. Kaminsky LA, Bryant CX, Mahler DA, Durstine JL, Humphrey RH: ACSM's Guidelines for Exercise Testing and Prescription. 8 edition. Baltimore, MD: Lippincott, Williams \& Wilkins; 2009.

33. Wessel J: Isometric strength measurements of knee extensors in women with osteoarthritis of the knee. J Rheumatol 1996, 23:328-331.

34. Carter ND, Khan KM, Petit MA, Heinonen A, Waterman C, Donaldson MG, Janssen PA, Mallinson A, Riddell L, Kruse K, Prior JC, Flicker L, McKay HA: Results of a 10 week community based strength and balance training programme to reduce fall risk factors: a randomised controlled trial in 65-75 year old women with osteoporosis. Br J Sports Med 2001, 35:348-351.

35. Cuka S, Dvornik S, Drazenovic K, Mihic J: Evaluation of the Dade Behring Dimension RxL clinical chemistry analyzer. Clin Lab 2001, 47:35-40.

36. McAuley KA, Williams SM, Mann JI, Walker RJ, Lewis-Barned NJ, Temple LA, Duncan AW: Diagnosing insulin resistance in the general population. Diabetes Care 2001, 24:460-464.

37. Ware JE, Kosinski M, Bayliss MS, McHorney CA, Rogers WH, Raczek A: Comparison of methods for the scoring and statistical analysis of SF-36 health profile and summary measures: summary of results from the Medical Outcomes Study. Med Care 1995, 33:AS264-279.

38. Denegar CR, Perrin DH: Effect of transcutaneous electrical nerve stimulation, cold, and a combination treatment on pain, decreased range of motion, and strength loss associated with delayed onset muscle soreness. J Athl Train 1992, 27:200-206.

39. Bellamy N, Buchanan WW, Goldsmith CH, Campbell J, Stitt LW: Validation study of WOMAC: a health status instrument for measuring clinically important patient relevant outcomes to antirheumatic drug therapy in patients with osteoarthritis of the hip or knee. J Rheumatol 1988, 15:1833-1840.

40. Black C, Clar C, Henderson R, MacEachern C, McNamee P, Quayyum Z, Royle $\mathrm{P}$, Thomas S: The clinical effectiveness of glucosamine and chondroitin supplements in slowing or arresting progression of osteoarthritis of the knee: a systematic review and economic evaluation. Health Technol Assess 2009, 13:1-148.

41. Frech TM, Clegg DO: The utility of nutraceuticals in the treatment of osteoarthritis. Curr Rheumatol Rep 2007, 9:25-30.

42. Messier SP, Gutekunst DJ, Davis C, DeVita P: Weight loss reduces kneejoint loads in overweight and obese older adults with knee osteoarthritis. Arthritis Rheum 2005, 52:2026-2032.

43. Felson DT: Nonmedicinal therapies for osteoarthritis. Bull Rheum Dis 1998, 47:5-7.

44. Baker KR, Nelson ME, Felson DT, Layne JE, Sarno R, Roubenoff R: The efficacy of home based progressive strength training in older adults with knee osteoarthritis: a randomized controlled trial. J Rheumatol 2001, 28:1655-1665.

45. Minor MA, Brown JD: Exercise maintenance of persons with arthritis after participation in a class experience. Health Educ Q 1993, 20:83-95.

46. Minor MA, Key DR: ACSM's exercise management for persons with chronic diseases and disabilities: Arthritis Champaign, IL: Human Kinetics; 1997. 
47. Penninx BW, Messier SP, Rejeski WJ, Williamson JD, DiBari M, Cavazzini C, Applegate WB, Pahor M: Physical exercise and the prevention of disability in activities of daily living in older persons with osteoarthritis. Arch Intern Med 2001, 161:2309-2316.

48. Miller GD, Nicklas BJ, Davis CC, Ambrosius WT, Loeser RF, Messier SP: Is serum leptin related to physical function and is it modifiable through weight loss and exercise in older adults with knee osteoarthritis? Int J Obes Relat Metab Disord 2004, 28:1383-1390.

49. Foster GD, Wyatt HR, Hill JO, McGuckin BG, Brill C, Mohammed BS, Szapary PO, Rader DJ, Edman JS, Klein S: A randomized trial of a lowcarbohydrate diet for obesity. N Engl J Med 2003, 348:2082-2090.

50. Reginster JY, Deroisy R, Rovati LC, Lee RL, Lejeune E, Bruyere O, Giacovelli G, Henrotin Y, Dacre JE, Gossett C: Long-term effects of glucosamine sulphate on osteoarthritis progression: a randomised, placebo-controlled clinical trial. Lancet 2001, 357:251-256.

51. Braham R, Dawson B, Goodman C: The effect of glucosamine supplementation on people experiencing regular knee pain. $\mathrm{Br} J$ Sports Med 2003, 37:45-49, discussion 49.

52. Matsuno H, Nakamura H, Katayama K, Hayashi S, Kano S, Yudoh K, Kiso Y: Effects of an oral administration of glucosamine-chondroitin-quercetin glucoside on the synovial fluid properties in patients with osteoarthritis and rheumatoid arthritis. Biosci Biotechnol Biochem 2009, 73:288-292.

53. Ng NT, Heesch KC, Brown WJ: Efficacy of a progressive walking program and glucosamine sulphate supplementation on osteoarthritic symptoms of the hip and knee: a feasibility trial. Arthritis Res Ther 2010, 12:R25.

doi:10.1186/1550-2783-8-8

Cite this article as: Magrans-Courtney et al.: Effects of diet type and supplementation of glucosamine, chondroitin, and MSM on body composition, functional status, and markers of health in women with knee osteoarthritis initiating a resistance-based exercise and weight loss

program. Journal of the International Society of Sports Nutrition 2011 8:8.

\section{Submit your next manuscript to BioMed Central and take full advantage of:}

- Convenient online submission

- Thorough peer review

- No space constraints or color figure charges

- Immediate publication on acceptance

- Inclusion in PubMed, CAS, Scopus and Google Scholar

- Research which is freely available for redistribution

Submit your manuscript at www.biomedcentral.com/submit 